\title{
Functional Organisation of the Mouse Superior Colliculus
}

Thomas Wheatcroft, Aman B Saleem, Samuel G Solomon

Institute of Behavioural Neurosciences, 26 Bedford Way, WC1H OAP, University College London, UK

\section{Abstract}

The superior colliculus (SC) is a highly conserved area of the mammalian midbrain that is widely implicated in the organisation and control of behaviour. SC receives input from a large number of brain areas, and provides outputs to a large number of areas. The convergence and divergence of anatomical connections with different areas and systems provides challenges for understanding how SC contributes to behaviour. Recent work in mouse has provided large anatomical datasets, and a wealth of new data from experiments that identify and manipulate different cells within SC, and their inputs and outputs, during simple behaviours. These data offer an opportunity to better understand the roles that SC plays in these behaviours. However, some of the observations appear, at first sight, to be contradictory. Here we review this recent work and hypothesize a simple framework which can capture the observations, that requires only a small change to previous models. Specifically, the functional organisation of SC can be explained by supposing that three largely distinct circuits support three largely distinct classes of simple behaviours - arrest, turning towards, and the triggering of escape or capture. These behaviours are hypothesised to be supported by the optic, intermediate and deep layers respectively.

\section{The superior colliculus}

The superior colliculus (SC), at the roof of the midbrain, is an evolutionarily old structure with strong commonalities across mammals, including cat, monkey, tree shrew, rat, and mouse. SC is highly interconnected with much of the brain, including the cerebellum, thalamus, hypothalamus and neocortex, and is implicated in the coordination of several 'higher-level' functions including attention and decision making. SC, however, is also an important target for sensory pathways, and sends outputs towards the motor pools, including brainstem and spinal cord, encouraging the view that its major role may be to support rapid sensorimotor behaviours.

Substantial recent work in mouse has explored the contribution of SC to behaviour, and the functional organisation of the circuits that may support these behaviours. This work has exploited new techniques for identifying, recording, manipulating and studying the connectivity of SC, and areas that are connected to it. The purpose of this review is to both collate this recent work and to synthesise it. The themes we will touch on are likely to be common across species, but a comparative analysis is beyond our scope, and we direct the reader to excellent recent reviews (May, 2006; Basso et al., 2021; Isa 
et al., 2021). Similarly, while mouse SC has been shown to also be involved in higher-level functions, we focus on simpler behaviours because they have been the focus of most recent work, and have proved useful in starting to link structure to function.

Anatomical sections through mouse SC reveal horizontal layers with distinct cellular, and histochemical organisation (Puelles et al., 2012) [Fig 1A]. We will use the term 'visuosensory SC' to define the layers closest to the dorsal surface, which comprise the 'optic' layer as well as the 'supraoptic' layers dorsal to it (superficial gray and zonal layers; Dong, 2008). Ventral to the optic layer are the 'intermediate' and then 'deep' layers, which can be collectively termed the 'motor-related SC' (Dong, 2008). Recent work suggests that the medial-lateral axis of SC can also be parcellated, into four columns that extend across layers (Benavidez et al., 2021). These columns are defined by the patterns of inputs and outputs and as yet have no known histochemical correlates.

The main sensory input to 'visuosensory $S^{\prime}$ ' is visual. Indeed, in mice, SC is the primary target of the retina (Ellis et al., 2016), and this input is supplemented by extensive projections from visual cortex. Visuosensory SC mainly represents the contralateral visual field, with nasal-totemporal azimuthal axis of the visual field mapped onto the anterior-to-posterior axis of SC, and lower-to-higher elevation axis of the visual field mapped onto the lateral-to-

${ }^{1}$ Triggered behaviours usually involve goaldirected movements and may include turns. But unlike 'turning', activations medial axis of SC (Xu et al., 2011) [Figs 2A,B]. For example, the anterior-lateral SC is activated by objects in front of the animal, below the eye, and the posteriormedial SC is activated by objects behind the animal, above the eye (e.g. MrsicFlogel et al., 2005). Neurons in the 'motorrelated' parts of SC can respond to visual stimuli, but also to other sensory modalities, receiving subcortical facial somatosensory and auditory input from the trigeminal nuclei and the inferior colliculus respectively (e.g. Benavidez et al., 2021). The topographic map of visual space found in the visuosensory SC is impressively matched to the maps of auditory (at least for the azimuthal axis) (Ito et al., 2020) and somatosensory (Drager and Hubel, 1975) space in the motor-related SC.

\section{The proposed functional \\ organisation of SC}

As we will describe, activation of neurons in the mouse SC can evoke varied behavioural responses. Some of these behavioural responses are relatively simple and well described. First, some activations cause a cessation of movement, a stoppage we will call 'arrest'. Second, some activations produce fixed rotational movements of the eye, tongue, head or of the whole body. We will call these egocentric rotations 'turning' [Fig 2C]. Third, some activations induce more complex behaviours, such that SC appears to provide a trigger, an impetus, or opens a gate for actions designed to achieve a certain outcome ${ }^{1}$. In some cases, this

trigger a motor action sequence that depends on the structure of the 
movement is towards an appetitive object (including prey), and we will call these actions 'capture ${ }^{2}$. In other cases, this movement is towards a place of apparent refuge, an action that we will call 'escape ${ }^{3}$ '.

An influential framework for understanding the functional organisation of the rodent SC was provided by Dean et al., 1989, synthesising a large body of work in rat. The core of this framework was a subdivision into medial and lateral SC. The lateral subdivision (which would approximately correspond to the lateral two columns in mouse SC), which represents a sensory stimulus in the lower parts of the contralateral visual field, provided outputs that 'crossed' hemispheres, and appeared to be involved in turning and approach towards that sensory stimulus. The medial subdivision (or medial two columns), which represents a sensory stimulus in the upper parts of the visual field, provided uncrossed outputs and appeared to be involved in behaviours, including arrest or fast locomotion, that facilitate avoidance of potential threats.

Here we ask if a modified framework for the organisation of SC can explain new data in mouse. We hypothesise an organisational framework where: 1 ) arrest is subserved by circuitry in the optic layer of SC; 2 ) contralateral turning movements are likely to be subserved by circuitry in the intermediate layers that span lateral and medial SC; and 3) deep layers of SC

environment, and cannot simply be explained by a stereotypical ego-centric action.

2'Capture' has been termed 'pursuit' elsewhere (e.g. Procacci and Hoy, 2019): appear to be involved in triggering more complex behaviours including capture (lateral SC) and escape (medial SC) [Fig 1B]. While manipulations of SC are sufficient to generate these behaviours, SC is likely only one part of a network of brain areas involved. Indeed, a hallmark of SC is the fact that so many areas of the brain give input to, or receive output from it. In the following sections, we therefore describe evidence for the hypothesised framework from direct manipulations of SC, from the topography of SC's sensorimotor function, and from SC's anatomical connectivity.

\section{How manipulations of SC effect}

\section{behaviour}

In the following sections we review how manipulations of specific neural populations in SC lead to distinct behaviours, and note in advance that effects of such manipulations need to be treated with caution (reviewed in Jazayeri and Afraz, 2017; Wolff and Ölveczky, 2018).

\section{Arrest}

Arrest is often thought of as an avoidance response, and is called freezing when the mouse is in a context with a potential threat. However, arrest may also be part of more exploratory behaviours, allowing for a pause for surveillance, or attention to the external environment (Botta et al., 2020).

we choose 'capture' to avoid confusion with pursuit eye-movements.

${ }^{3}$ Note that escape is considered to be an action towards a target (i.e. the refuge) rather than away from the location of a potential threat (e.g. Vale et al., 2017). 
Direct manipulations of SC support the idea that the optic layer is important in arrest. Activation (Sans-Dublanc et al., 2021) or inhibition (Xie et al., 2021) of neurons concentrated in the optic layer induces or impairs arrest respectively. Other manipulations of SC that evoke arrest have either included (Wei et al., 2015), or have focussed on (Zingg et al., 2017), the optic layer. Manipulation of CAMK2+ SC neurons at the border of the optic layer and intermediate layers can also elicit arrest behaviour (Wei et al., 2015; Cai et al., 2022). In common with some other neurons in the optic layer, these neurons appear to project to the lateral posterior nucleus of the thalamus (LP) and activation of their terminals in LP evokes arrest (Wei et al., 2015). For simplicity, we therefore include these neurons as part of the optic layer.

Arrest behaviour is more likely to be elicited by activation of medial SC, than lateral SC (Wei et al., 2015). This mediolateral asymmetry is consistent with the previously hypothesized medio-lateral separation of function (Dean et al., 1989). Our hypothesis predicts that the absence of arrest behaviours during activation of lateral SC can be explained by the fact that the optic layer does not extend into the lateral most columns of SC [Fig 1] (Benavidez et al., 2021).

\section{Turning}

It is well established that activation of the motor-related SC in freely-moving animals produces contralateral turning movements, or biases an animal towards making them (Stubblefield et al., 2013; Masullo et al., 2019; Cregg et al., 2020; Essig et al., 2021). In head-fixed mice, activation of motor-related SC biases eye movements (Zahler et al., 2021) towards the contralateral side. Inhibiting motorrelated SC does the opposite, biasing the animal towards ipsilateral movements (Stubblefield et al., 2013; Lee and Sabatini, 2021). We note that when head-fixed mice rotate a ball or wheel beneath them, most active neurons in motor-related SC prefer ipsilateral turns (Steinmetz et al., 2019) and unilateral inhibition of motor-related SC biases animals away from ipsilateral turns (Huda et al., 2020). The likely explanation is that these 'ipsilateral' turns require mice to push the ball or wheel down on its ipsilateral side, a movement associated with contralateral turning during free behaviour (Huda et al., 2020).

The intermediate layers of $\mathrm{SC}$ appear to be particularly important in turning. Activation of PITX2+ neurons in SC, which are concentrated in the intermediate layers, evokes turning (Masullo et al., 2019). The intermediate (but not deep layers) are targeted by the substantia nigra pars reticulata (SNr; Lee et al., 2020a), and activation of $\mathrm{SNr}$ terminals in $\mathrm{SC}$ induces turning (Villalobos and Basso, 2020). Likewise, the intermediate (but not deep layers) project to neurons gigantocellular nucleus that are important in turning (Cregg et al., 2020).

Lateral SC is known to be involved in turning, and there is some evidence for a role of medial SC in turning. Activation of lateral SC mostly evokes contralateral turning (Isa et al., 2020) while inhibition of lateral SC neurons can impair instinctive turning towards sounds (Vale et al., 2020) and other turning behaviours (Sooksawate et al., 2013; Isa et al., 2020). Circuits for turning may, however, include medial SC as well as lateral SC. Activation of PITX2+ neurons in medial SC induces head turns 
(Masullo et al., 2019). Activating progressively more medial locations of SC evoked larger pitch angles of head rotation, suggesting that medial $\mathrm{SC}$ is involved in making movements towards more elevated angles (Masullo et al., 2019). Pitch rotations of the head produced by medial SC are difficult to measure and have only been achieved in limited number of experiments - more data would help strengthen the case for a role of medial SC in turning.

SC is primarily concerned with turning towards the contralateral side, but activation of anterior-medial SC can also evoke ipsiversive head turns (Isa et al., 2020), and an ipsiversive bias has been reported for some medial SC neurons (cuneiform nucleus-projectors; Isa et al., 2020) but not others (primary auditory cortex-recipient; Zingg et al., 2017). Activation of inhibitory, GABAergic SC neurons can bias animals towards contralateral movements (Essig et al., 2021; Sans-Dublanc et al., 2021) or ipsilateral movements (Duan et al., 2021; Hao et al., 2021); the specific movements elicited by activating subpopulations of neurons in SC is therefore likely to depend on both the specific projection patterns and output (excitatory, inhibitory) of those neurons.

\section{Escape and capture}

Circuits in medial SC are clearly important in triggering escape behaviours. Activation of medial, motor-related SC neurons can evoke escape or putatively escape-related backwards walking and fast forwards running (Zingg et al., 2017; Evans et al., 2018; Isa et al., 2020); inhibition of medial motor-related SC impairs the triggering of escape (Evans et al., 2018). By contrast, inhibition of lateral SC does not affect the production or speed of escape behaviour (Shang et al., 2019; Vale, 2020; Huang et al., 2021), though it can affect the direction of escape (Vale et al., 2020).

Circuits in lateral motor-related SC appear more important in triggering capture behaviours. Inhibition of lateral motorrelated SC neurons (including those projecting to subthalamus- or substantia nigra pars compacta, SNc; Shang et al., 2019; Huang et al., 2021) impairs capture, that is movements towards prey (Shang et al., 2019; Huang et al., 2021; Xie et al., 2021), food or conspecifics (Huang et al., 2021).

Escape and capture are both complex behaviours, that involve a combination of actions, such as turns combined with locomotion. However, activations that induce escape and capture behaviours produce turns that appear goal directed, rather than the stereotypical ego-centric turns that comprise 'turning' behaviours described above (Evans et al., 2018; Shang et al., 2019; Huang et al., 2021; Xie et al., 2021). Whether and how escape and capture behaviours recruit circuits for 'turning' is not yet clear. Activation of PITX2+ neurons in intermediate layers of SC induces turning without locomotion (Masullo et al., 2019), but large-scale inhibition of PITX2+ neurons does appear to impair capture (Xie et al., 2021). Thus, while we hypothesise that turning is supported primarily by neurons in intermediate SC, and triggering of capture and escape is supported primarily by neurons in deep SC, direct manipulations of motor-related SC are yet to reveal the relative contribution of intermediate and deep parts of SC in these behaviours. 
We hypothesise that SC plays a similar role in both capture and escape: the output of deep layer SC triggers goal-directed action. The specific goal of that action depends on whether that signal arises in the lateral (e.g. prey) or medial (e.g. refuge) subdivisions of the deep layer, because these subdivisions have different connections to the rest of the brain, as we review below. However, the computations performed by the lateral- and medial parts of deep layer SC are predicted to be the same in both cases.

\section{How sensory and motor function} are topographically organised in

\section{SC}

The major sensory inputs to SC - visual, auditory and somatosensory - are organised into aligned topographic maps (Drager and Hubel, 1975; Ito et al., 2020). These maps provide a representation of the egocentric direction of an object relative to the animal's head: the direction of an auditory or somatosensory stimulus is directly related to the head-centric direction of the object that produces them; the location of an object's image on the retina, if eye-movements are ignored, is also a proxy for head-centric object direction. These sensory maps are aligned parallel to the surface of SC, orthogonal to the proposed laminar organisation of function. The sensory maps may therefore be important in guiding and constraining the behaviour(s) that are elicited by sensory stimuli presented at particular directions relative to the animal.

The alignment between sensory and motor maps in SC is likely to be important in turning behaviours. Visuosensory SC includes 'narrow-field' cells (Gale and Murphy, 2014) that project into topographically-aligned parts of motorrelated SC and appear important in turning towards prey (Hoy et al., 2019). Consistently, activation of motor-related SC evokes turning towards the directions that are represented by the equivalent location in the sensory maps [Fig 2]. Activation of PITX2+ neurons at specific locations in the intermediate layers evoke contralateral turns towards specific directions (Masullo et al., 2019). Activation of more posterior PITX2+ neurons evokes larger contralateral (yaw) turns, consistent with the more temporal receptive fields found in posterior SC. Activation of more medial PITX2+ neurons evokes larger pitch turns, consistent with the more elevated receptive fields found in the medial SC. Similarly, in head-fixed mice activation of more posterior SC neurons induces more temporal eye turns (Wang et al., 2015).

The relationship between topographic sensory maps and other actions (escape, capture, arrest) is less clear. Activation experiments show that motor-related medial SC is important in escape behaviour, and visuosensory medial SC represents the overhead visual field. If this topographic alignment were important for escape behaviour, then escape behaviours should be more easily elicited by stimuli in the upper visual field (cf. Dean et al., 1989), which would include aerial, and tall ground-based predators. Indeed, an expanding black disc on a screen ('looming stimulus') presented to the upper visual field usually elicits a rapid escape to refuge when one is present (Yilmaz and Meister, 2013). Whether looming stimuli from other visual directions can induce 
escape responses is less clear, but limited work suggests that a looming stimulus in front (Zhou et al., 2019) or below (Yilmaz and Meister, 2013; Zhou et al., 2019) a mouse does not elicit the same rapid escape. Capture can be directed towards stimuli in the lower visual field (Hoy et al., 2016; Vale et al., 2020), and perhaps specific parts of the lower visual field (Hoy et al., 2016, 2019; Michaiel et al., 2020; Holmgren et al., 2021; Johnson et al., 2021). Whether capture behaviours can be evoked by a stimulus presented to the upper visual field remains to be seen. Behavioural work suggests that arrest can be induced by a visual stimulus presented to either the upper or lower visual field (De Franceschi et al., 2016; Procacci et al., 2020).

\section{How areas connected to SC influence behaviour}

Connections of different parts of SC with other brain areas provides complementary, circumstantial evidence for the parcellation of behavioural function proposed in Fig 1A. This evidence is summarised below and in Fig 3. Tables 1 5 summarise the key experimental methods and results of these studies as look-up tables, and direct the reader to additional related work.

\section{Visuosensory SC, Arrest}

Connections of visuosensory SC, and the optic layer in particular, are consistent with a role in arrest. The thalamic area LP and pontine area LDT are innervated by the optic layer (Xie et al., 2021), and are involved in arrest (Yang et al., 2016; Shang et al., 2018). Midbrain area PBG has reciprocal connections with visuosensory
SC (including the optic layer; Zhang et al., 2019; Tokuoka et al., 2020), and may be involved in the production of arrest following escape (Shang et al., 2018). VISp innervates the visuosensory SC, including the optic layer, and activation of these terminals in SC (Liang et al., 2015) or of SC neurons postsynaptic to them (Zingg et al., 2017) induces arrest, while inhibition of VISp impairs arrest to light flashes (Liang et al., 2015). Interestingly, ventral stream higher-order visual areas (V-HVAs) primarily project to optic layer (Wang and Burkhalter, 2013) but whether they also have a role in arrest is not yet known. By contrast, while inhibition of primary auditory cortex also impairs sound-induced arrest ( $\mathrm{Li}$ et al., 2021), AUDp projection to SC does not innervate the optic layer (Benavidez et al., 2021), and inhibition of SC does not impair these sound-induced arrest behaviours. The stimulus selectivity of visuosensory SC is generally broad (e.g. Gale and Murphy, 2014; De Franceschi and Solomon, 2018), and the sensory signals in these layers are therefore likely able to guide many or even most behaviours. Particular pathways through visuosensory SC may nevertheless be more important for some behaviours than others (e.g. Reinhard et al., 2019); whether projections from visuosensory to motor-related SC are particularly important for arrest, remains to be determined.

Central amygdala $(\mathrm{CeA})$ is an end target of many of the pathways that project from the optic layer of SC. LP is indirectly connected to $\mathrm{CeA}$ through the basolateral amygdala (Fadok et al., 2018), and PBG projects directly to $\mathrm{CeA}$ (Shang et al., 2015). Activation of medial SC populations concentrated in (NTSR1+) (Gale and 
Murphy, 2014), or including (CAMK2+) (Wei et al., 2015), the optic layer activates $\mathrm{CeA}$ and induces arrest (Sans-Dublanc et al., 2021), and manipulating $\mathrm{CeA}$ alters freezing responses to visual looming stimuli (Zelikowsky et al., 2018). CeA may promote arrest or freezing via several potential pathways, perhaps even through its projection to PAG (Tovote et al., 2015; Vaaga et al., 2020; Yu et al., 2021).

\section{Intermediate layers of SC, Turning}

Intermediate layers of SC are likely to be particularly important in turning. $\mathrm{CHX10+}$ gigantocellular (Gi) neurons, which are a potential route through which lateral SC promotes contralateral turning, receive input from intermediate layers (but not deep layers) of SC (Cregg et al., 2020). Intermediate layers (but not deep layers) are innervated by the substantia nigra pars reticulata (SNr; Lee et al., 2020a), and manipulation of that input induces turning (Villalobos and Basso, 2020). Dorsal stream higher visual areas (D-HVAs), which may play a role in representing turn directions (Itokazu et al., 2018; Odoemene et al., 2018), specifically target intermediate layers (Wang and Burkhalter, 2013).

Areas involved in turning appear to preferentially connect to lateral SC. Many of the connections of lateral SC (Benavidez et al., 2021) are known to have a role in producing movements towards particular egocentric directions, either of the body (including Gi; Cregg et al., 2020) or its parts (motor cortex, MOp/MOs; fastigial nucleus of the cerebellum, FN; motor thalamus, VM/VAL; Guo et al., 2014, 2017; Hira et al., 2015; Morandell and Huber, 2017; Gao et al., 2018; Heindorf et al., 2018; Mayrhofer et al., 2019). Lateral
SC also provides output to the medullary reticular nucleus (MDRNv; Esposito et al., 2014) that may be important in movements of the forelimb contralateral to SC (Ruder et al., 2021), and to the parvicellular reticular nucleus (PARN) that may also be important in forelimb (Ruder et al., 2021) and tongue-jaw movements (Han et al., 2017).

While there is good evidence that lateral SC is involved in turning movements, PITX2+ SC neurons are found in medialas well as lateral SC (Masullo et al., 2019), and these neurons are known to be involved in turning. The connection pattern of PITX2+ neurons is similar to that found for non-specific tracing from lateral SC (Masullo et al., 2019; Xie et al., 2021). This suggests that while areas involved in turning have stronger connections with lateral SC, they are also connected to medial SC.

$\mathrm{SC}$ also sends projections to basal ganglia nuclei, including ventral tegmental area (VTA; e.g. Zhang et al., 2019; Zhou et al., 2019) and the subthalamic nucleus (STN). Whether these SC projections help generate specific turning actions, or more complex behaviours, is not yet clear (Hughes et al., 2019; Zhou et al., 2019; Barbano et al., 2020).

\section{Deep layers of SC, Capture and Escape}

Deep layers of SC are connected to areas that are thought to be important in triggering more complex movements. Deep lateral SC is connected to areas (Benavidez et al., 2021) involved in triggering capture (including medial zona incerta, ZIm; substantia innominata, SI; ventromedial hypothalamus, ventrolateral part, VMHvl; (Lee et al., 2014; Zhao et al., 2019; Zhu et al., 2021) and activation of 
SC terminals in the ZI (Shang et al., 2019; Xie et al., 2021) or substantia nigra pars compacta (SNc; Huang et al., 2021), facilitates capture. Lateral SC also projects to the lateral hypothalamic area (LHA; Venner et al., 2019; Benavidez et al., 2021), also potentially involved in capture (Li et al., 2018). Lateral SC receives input from the dentate and interposed nuclei of the cerebellum (DN/IP), areas which might be involved in triggering goal-directed movements of the forelimb (Dacre et al., 2021) and other body parts.

Deep medial SC is connected to areas involved in evoking fast locomotion (including cuneiform, CUN; magnocellular nuclei, MARN; Capelli et al., 2017; Caggiano et al., 2018) and triggering escape (including dPAG; lateral parabrachial nucleus, $\mathrm{PBI}$; lateral septum, LS; ventromedial hypothalamus, dorsomedial/central part, VHMdm/c; Han et al., 2015; Kunwar et al., 2015; Deng et al., 2016; Tovote et al., 2016; Evans et al., 2018; Azevedo et al., 2020; Sun et al., 2020). Activation of terminals of SC neurons in the PAG evokes mild running in head-fixed mice (Wang et al., 2019a) and "wild running or backward fleeing behaviours" in freely-moving mice (Wei et al., 2015). Some medial SC neurons project to both CUN and dPAG (Isa et al., 2020).

Whether triggering of behaviour is the preserve of deep layers, or also involves intermediate layers is not yet clear. Capture-associated connections (ZIm and $\mathrm{VMHvl}$ ) also contact intermediate layers (Benavidez et al., 2021). In the case of escape, DRD2+ and PITX2+ neurons both have patchy labelling in intermediate layers of SC, but have different projections, and activation of the former can trigger escape, suggesting that some intermediate layer neurons are involved in triggering escape (Masullo et al., 2019; Montardy et al., 2021; Xie et al., 2021). However, deep layers of SC alone are innervated by VMHdm/c (Benavidez et al., 2021), and dPAG also gets more input from the deep layers of $S C$ than intermediate layers (Evans et al., 2018). VMHdm/c and dPAG have roles in triggering escape behaviour, so their connection to the deep rather than intermediate SC would suggest the deep layers are more important in triggering these behaviours.

\section{Conclusion}

In summary, we propose that many of the recent observations made while investigating of the role of mouse SC in simple behaviours can be explained by supposing that: 1) the optic layer is important in arrest; 2) the intermediate layers are important in turning; 3 ) the deep layers are involved in the triggering of more complex behaviours including capture and escape. Our hypothesis has the advantage that it predicts that the circuitry in each of the optic, intermediate and deep layers has a simple computational purpose. The proposed organisation allows homogenous organisation and expression of genetic markers within a layer, and allows homogenous circuitry and function within each layer. That is, each layer performs a particular computation, but the functional consequence of that computation depends on the particular pattern of inputs and outputs at different locations (e.g. medial or lateral) within the layer. The proposed organisation of SC is therefore similar in concept to the idea of columnar or 'canonical' microcircuitry 
thought to be important in the function of the cerebral cortex (e.g. Miller, 2016).

Dean et al., 1989 proposed that the crossed pathway of SC (spanning the medial-lateral axis, but concentrated in lateral SC) was associated with contralaterally-directed movements, whilst the uncrossed pathway (concentrated in medial SC) was associated with defensive behaviours, such as freezing, escape and ipsilaterally-directed movements. We also propose that neurons promoting contralaterally-directed movements are distributed across the medial-lateral axis of SC, and that escape is the preserve of medial SC, although we further hypothesise that turning and escape are associated with the intermediate and deep layers respectively. The major differences between our proposed organisation, and that of Dean and colleagues, is that in our organisation: arrest (including freezing) is primarily supported by neurons in the optic layer. In addition, we propose that equivalent circuitry within lateral and medial parts of the deep layers supports both capture and escape - different behaviours are triggered by medial and lateral SC because each region has distinct pattern of connections with other brain areas.

Lamprey, fish and flies turn away from threatening stimuli, and in lamprey and fish, this action is supported by ipsiversive movement-promoting neurons in homologues of SC (Isa et al., 2021). Instead, mice turn towards a refuge (when present) when they are confronted by imminent threats (Evans et al., 2018). Our proposal does not include a role for ipsiversive movement-promoting neurons in mouse SC. If correct, we speculate that this species difference may be part of a general co-option of SC's turning circuitry in mammals, allowing mice to turn towards memorised, predicted or learned directions. These behaviours may be supported by inputs from evolutionarily newer areas in the telencephalon, including the retrosplenial and frontal cortices, and the basal ganglia. The role of these inputs would be to override the 'turn towards stimuli' contingency normally represented by turning circuitry in SC, including functionally inhibiting contraversive turn-promoting neurons (c.f. Huda et al., 2020; Duan et al., 2021; Lee and Sabatini, 2021).

There remain many missing pieces that may provide substantial challenges to the proposed organisation. For example, we predict that separate neurons are involved in turning and capture, and that they are associated with the intermediate and deep layers respectively, but there is mixed evidence for the laminar segregation of these neurons. In some SC targets (ZI, vIPAG, VTA), different neurons are involved in different behaviours, but whether these are appropriately connected to relevant SC neurons is untested. We have not considered the role of the extensive interhemispheric connections of SC. We also predict that visual stimuli will elicit rapid escape only if they are in the upper visual field, but there is very little data on the influence of stimulus location on escape. Finally, emerging work has now started to explore SC's role in stimulus discrimination tasks in mouse (e.g. Stubblefield et al., 2013; Hu et al., 2019; Wang et al., 2020, 2021; Duan et al., 2021; Essig et al., 2021; Hu and Dan, 2022). How the behaviours we have focused on (arrest, capture, escape) contribute to these tasks is not yet clear. Combining the 
formalism of classical discrimination tasks, and the ecological relevance of the behaviours we have generally discussed here, is likely to be a fruitful direction for future research.

Much remains to be understood about the specific contribution of SC to even simple behaviours. For example, consider two potential representations provided by intermediate layers of SC, which are likely to support turning behaviours. In one scenario, intermediate layers represent the direction in which behaviour should be expressed, and other brain areas are responsible for selecting the specific behaviour that should be produced, such as choosing between orienting the eyes, head or tongue. Alternatively, the pattern of activity over SC neurons might define both direction and specific behaviour produced, similar to the action-selection model of basal ganglia function (Friend and Kravitz, 2014). Indeed, some targets of SC appear to be involved in specific types of turns (e.g. Takatoh et al., 2021). Retrograde tracing experiments also suggest that different targets of $S C$ receive input from different SC neurons: LPprojectors are separate from PBGprojectors (Shang et al., 2018) and SNcprojectors (Huang et al., 2021); Zlprojectors are separate from PAGprojectors, MLR-projectors (Shang et al., 2019), and SNc-projectors (Huang et al., 2021); SNc-projectors are separate from VTA-projectors (Huang et al., 2021). Functional evidence is however limited, and it remains possible that individual SC neurons are involved in multiple aspects of turning. For example, PITX2+ SC neurons promote orienting in freely-moving mice, but eye turns in head-fixed mice, (Masullo et al., 2019).
Resolution of these outstanding questions is likely to be helped by the development of mouse lines in which genetically-defined populations can be studied. Recent work has already provided lines which allow the targeting of neurons in different layers, often with different connections. Different zonal and upper superficial gray layer neurons can be targeted using expression of DRD1 (Montardy et al., 2021), and combinations of GAD2 and RORB (Gale and Murphy, 2018). Another population of visuosensory neurons is labelled by GRP (Gale and Murphy, 2014). In the lower superficial gray and optic layer, neurons can be targeted using expression of PV (Shang et al., 2015), NSTR1 (Gale and Murphy, 2014), CAMK2 (Wei et al., 2015), CBLN2 (Xie et al., 2021), SP (Zhou et al., 2017) and DRD2 (Montardy et al., 2021). The intermediate layers can be targeted with PITX2 (Masullo et al., 2019; Xie et al., 2021) and DRD2 (Montardy et al., 2021) expression. Cell types in the deep layers of SC, which have been defined on the basis of morphological and intrinsic electrophysiological properties, currently lack equivalent genetic markers (Bednárová et al., 2018).

Our proposal may provide a natural framework for more general understanding of the function of SC. First, threat imminence theory proposes that animals switch from freezing to escape behaviour as a threat becomes more imminent (Perusini and Fanselow, 2015). While many stimuli may elicit freezing, only some should trigger escape. This is consistent with the fact that neurons in optic layers respond to a broader range of visual stimuli than do neurons in motor-related SC (Lee et al., 2020b). Second, SC is generally thought to be important in mediating visual 
attention, at least in primates (e.g. Krauzlis et al., 2013). If attention can be similarly described in mice (Wang and Krauzlis, 2018), then optic layer SC neurons involved in arrest (whose projections include the thalamus) may be important in pausing other behaviours to allow attention, and motor-related SC neurons involved in turning may be important in directing attention to particular locations within the visual field (Wang et al., 2020, 2021). Third, the proposed compartmentalisation of function may help rapid decision making (Gold and Shadlen, 2007). Activity in each compartment could be considered evidence in favour of a behaviour, such that behaviour is executed when accumulated activity exceeds a threshold level. Indeed, a threshold applied to the accumulated activity of neurons in motor-related SC can explain triggering of escape behaviours (Evans et al., 2018). Fourth, even these simple behaviours are context dependent - for example animals usually choose to escape from a looming visual stimulus (Yilmaz and Meister, 2013), but freeze if the refuge is distant (Lecca et al., 2020) or absent (Vale et al., 2017). Functional compartmentalisation of SC would make it straightforward to bias simple behavioural choices and thereby tune behaviour to context. 


\section{Figures}

a

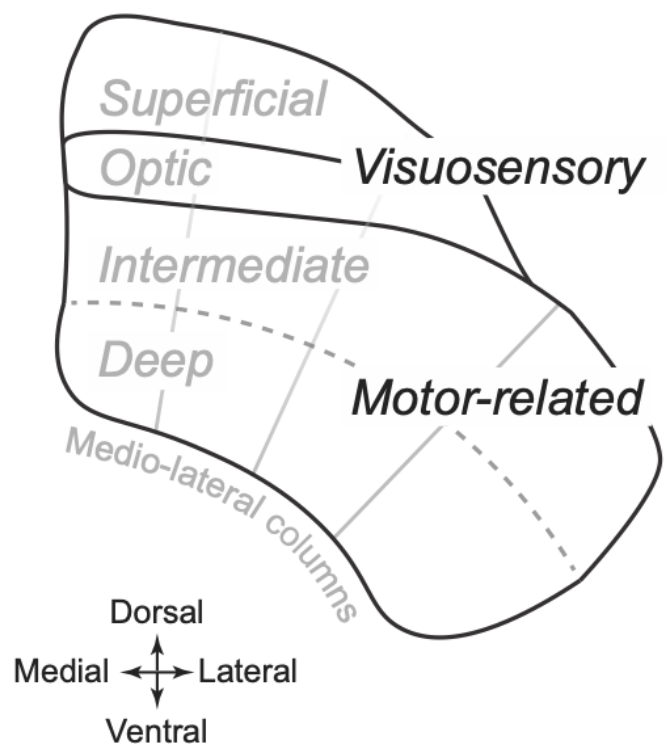

b

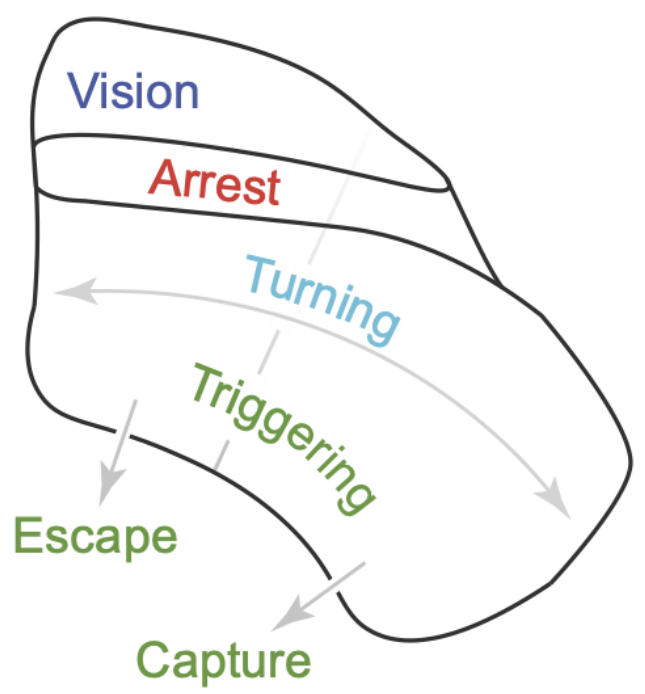

Figure 1: Organisation of superior colliculus in mouse. a. Schematic coronal section illustrating the dorso-ventral organisation of the superior colliculus (SC) of mouse. The optic layer is ventral to the superficial layers (which includes the superficial gray and zonal layer). Together these layers are termed the 'visuosensory SC'. Ventral to the optic layer is the intermediate and then the deep layer. Together these layers are termed 'motor-related SC'. The radial gray lines indicate an approximate division of the SC into four 'columns' that extend across the layers, partitioning SC on the mediallateral axis (Benavidez et al., 2021). b. Proposed functional organisation of SC. The superficial layers primarily support visual analysis; the optic layers primarily organise arrest behaviours; the motor-related SC supports egocentric turning movements as well as the triggering of more complex behaviours, either towards objects including prey ('capture', lateral SC) or towards refuge ('escape', medial SC). Turning and triggering may be primarily supported by the intermediate and deep layers respectively. 
a

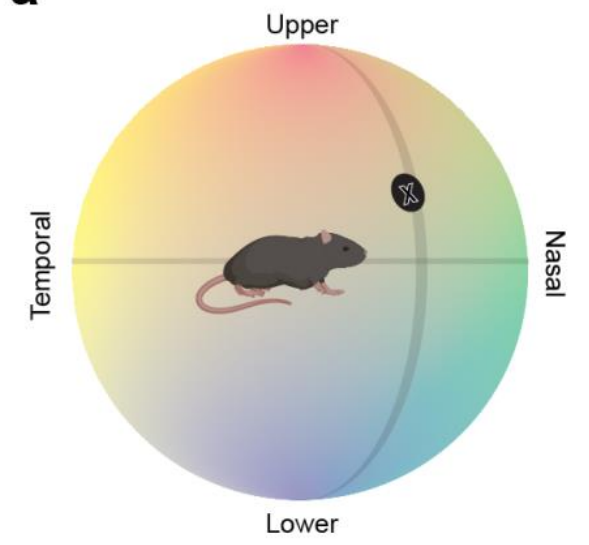

C

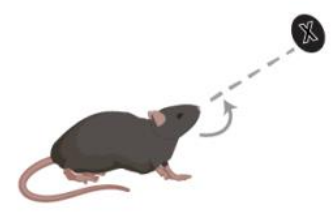

b

Anterior

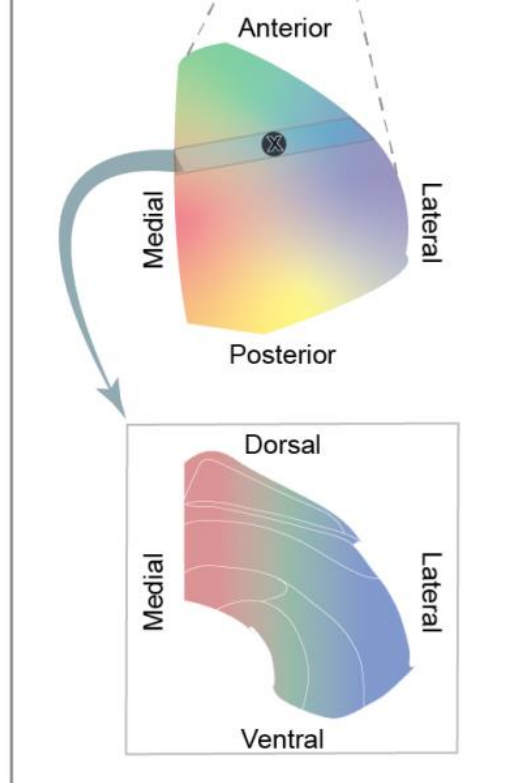

Figure 2: Topographic organisation of SC. a. Schematic illustrating a mouse, and the world to its left, as mapped onto a hemisphere around the mouse. The direction of objects are defined in terms of visual angle: their azimuth (position along the nasal-temporal axis) and their elevation (position along axis from the upper-lower field). Azimuth and elevation axes are depicted as black lines and the black disc represents an example object. b. Schematic representation of the mapping of the world onto different sections of SC. Top panel illustrates the position of SC in the mouse brain. Middle panel enlarges the right SC and shows how azimuth and elevation axes of visual field are mapped onto SC. The black disc indicates the approximate location of object in (a) in this map. Bottom pane/ illustrates the mapping of the world onto a coronal section through SC. c. Activation of intermediate layer would evoke a turn towards the egocentric location represented by that region of SC. 
a

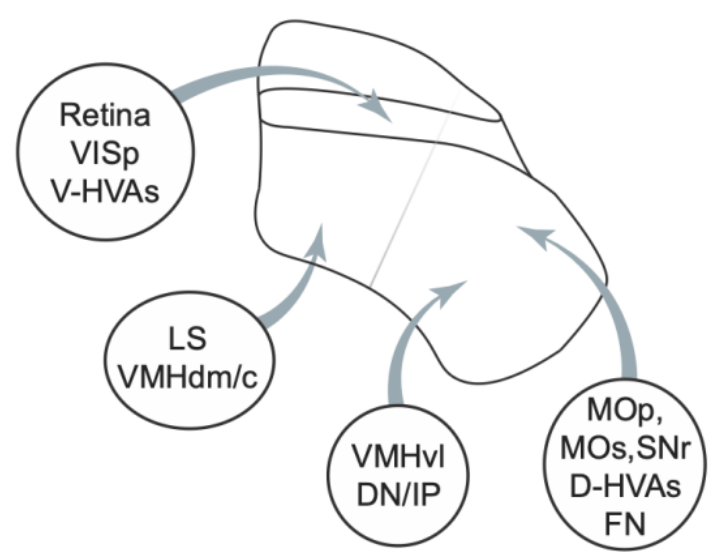

b

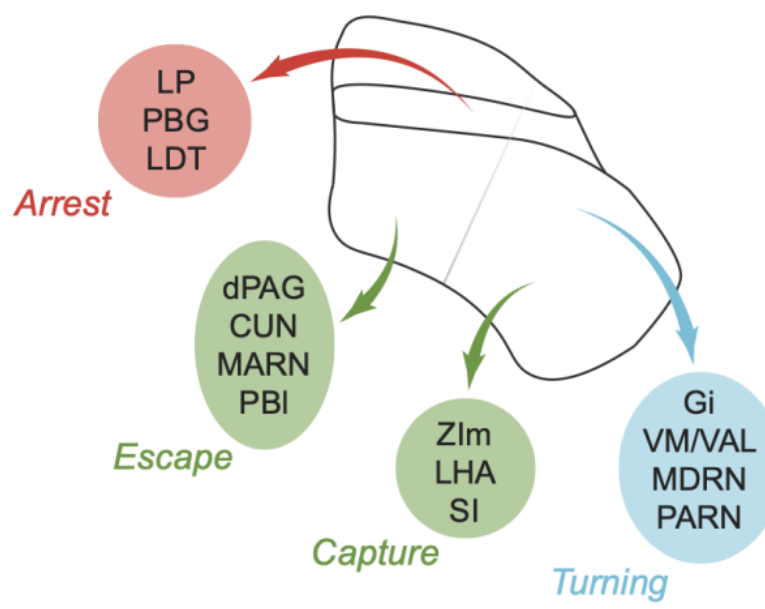

Figure 3: Summary of some of the major inputs and outputs of SC. a. Inputs. Areas are grouped by major target regions in SC. b. Outputs. Areas are grouped by major source regions in SC and proposed functional roles, indicated next to the group. Arrows in (a) and (b) show approximate locations of the input targets (a) or projection sources (b). Abbreviations are defined in Supplementary Table 1. Appropriate references can be found in the text and in Tables 1-5. 


\section{References}

Ahmadlou, M., Houba, J. H. W., van Vierbergen, J. F. M., Giannouli, M., Gimenez, G. A., van Weeghel, C., et al. (2021). A cell type-specific cortico-subcortical brain circuit for investigatory and novelty-seeking behavior. Science 372. doi:10.1126/science.abe9681.

Azevedo, E. P., Tan, B., Pomeranz, L. E., Ivan, V., Fetcho, R., Schneeberger, M., et al. (2020). A limbic circuit selectively links active escape to food suppression. eLife 9, 1-23. doi:10.7554/ELIFE.58894.

Barbano, M. F., Wang, H.-L., Zhang, S., Miranda-Barrientos, J., Estrin, D. J., FigueroaGonzález, A., et al. (2020). VTA Glutamatergic Neurons Mediate Innate Defensive Behaviors. Neuron 0. doi:10.1016/j.neuron.2020.04.024.

Basso, M. A., Bickford, M. E., and Cang, J. (2021). Unraveling circuits of visual perception and cognition through the superior colliculus. Neuron 109, 918-937. doi:10.1016/j.neuron.2021.01.013.

Bednárová, V., Grothe, B., and Myoga, M. H. (2018). Complex and spatially segregated auditory inputs of the mouse superior colliculus. The Journal of Physiology 596, 5281-5298. doi:10.1113/JP276370.

Benavidez, N. L., Bienkowski, M. S., Zhu, M., Garcia, L. H., Fayzullina, M., Gao, L., et al. (2021). Organization of the inputs and outputs of the mouse superior colliculus. Nature Communications 12, 1-20. doi:10.1038/s41467-021-24241-2.

Botta, P., Fushiki, A., Vicente, A. M., Hammond, L. A., Mosberger, A. C., Gerfen, C. R., et al. (2020). An Amygdala Circuit Mediates Experience-Dependent Momentary Arrests during Exploration. Cell 183, 605-619.e22. doi:10.1016/j.cell.2020.09.023.

Burgess, C. P., Lak, A., Steinmetz, N. A., Zatka-Haas, P., Bai Reddy, C., Jacobs, E. A. K., et al. (2017). High-Yield Methods for Accurate Two-Alternative Visual Psychophysics in Head-Fixed Mice. Cell Reports 20, 2513-2524. doi:10.1016/j.celrep.2017.08.047.

Caggiano, V., Leiras, R., Goñi-Erro, H., Masini, D., Bellardita, C., Bouvier, J., et al. (2018). Midbrain circuits that set locomotor speed and gait selection. Nature 553, 455-460. doi:10.1038/nature25448.

Cai, X., Li, L., Liu, W., Du, N., Zhao, Y., Han, Y., et al. (2022). A dual-channel optogenetic stimulator selectively modulates distinct defensive behaviors. iScience 25, 103681. doi:10.1016/J.ISCI.2021.103681.

Capelli, P., Pivetta, C., Esposito, M. S., and Arber, S. (2017). Locomotor speed control circuits in the caudal brainstem. Nature 551, 373-377. doi:10.1038/nature24064.

Cregg, J. M., Leiras, R., Montalant, A., Wanken, P., Wickersham, I. R., and Kiehn, O. (2020). Brainstem neurons that command mammalian locomotor asymmetries. Nature Neuroscience 23, 730-740. doi:10.1038/s41593-020-0633-7.

Dacre, J., Colligan, M., Clarke, T., Ammer, J. J., Schiemann, J., Chamosa-Pino, V., et al. (2021). A cerebellar-thalamocortical pathway drives behavioral contextdependent movement initiation. Neuron 109, 2326-2338.e8. doi:10.1016/j.neuron.2021.05.016.

De Franceschi, G., and Solomon, S. G. (2018). Visual response properties of neurons in the superficial layers of the superior colliculus of awake mouse. The Journal of Physiology 596, 6307-6332. doi:10.1113/JP276964.

Dean, P., Redgrave, P., and Westby, G. W. M. (1989). Event or emergency? Two response systems in the mammalian superior colliculus. Trends in Neurosciences 12, 137-147. doi:10.1016/0166-2236(89)90052-0. 
De Franceschi, G., Vivattanasarn, T., Saleem, A. B., and Solomon, S. G. (2016). Vision Guides Selection of Freeze or Flight Defense Strategies in Mice. Current Biology 26, 2150-2154. doi:10.1016/J.CUB.2016.06.006.

Deng, H., Xiao, X., and Wang, Z. (2016). Periaqueductal gray neuronal activities underlie different aspects of defensive behaviors. Journal of Neuroscience 36, 7580-7588. doi:10.1523/JNEUROSCI.4425-15.2016.

Dong, H. W. (2008). The Allen reference atlas: A digital color brain atlas of the C57BI/6J male mouse. Hoboken, NJ, US: John Wiley \& Sons Inc.

Drager, U. C., and Hubel, D. H. (1975). Physiology of visual cells in mouse superior colliculus and correlation with somatosensory and auditory input. Nature 253, 203204. doi:10.1038/253203a0.

Duan, C. A., Pan, Y., Ma, G., Zhou, T., Zhang, S., and Xu, N. long (2021). A corticocollicular pathway for motor planning in a memory-dependent perceptual decision task. Nature Communications 12, 1-16. doi:10.1038/s41467-021-22547-9.

Ellis, E. M., Gauvain, G., Sivyer, B., and Murphy, G. J. (2016). Shared and distinct retinal input to the mouse superior colliculus and dorsal lateral geniculate nucleus. Journal of Neurophysiology 116, 602-610. doi:10.1152/jn.00227.2016.

Esposito, M. S., Capelli, P., and Arber, S. (2014). Brainstem nucleus MdV mediates skilled forelimb motor tasks. Nature 508, 351-356. doi:10.1038/nature13023.

Essig, J., Hunt, J. B., and Felsen, G. (2021). Inhibitory neurons in the superior colliculus mediate selection of spatially-directed movements. Communications Biology 4, 114. doi:10.1038/s42003-021-02248-1.

Evans, D. A., Stempel, A. V., Vale, R., Ruehle, S., Lefler, Y., and Branco, T. (2018). A synaptic threshold mechanism for computing escape decisions. Nature 558, 590594. doi:10.1038/s41586-018-0244-6.

Fadok, J. P., Markovic, M., Tovote, P., and Lüthi, A. (2018). New perspectives on central amygdala function. Current Opinion in Neurobiology 49, 141-147. doi:10.1016/j.conb.2018.02.009.

Fratzl, A., Koltchev, A. M., Vissers, N., Tan, Y. L., Marques-Smith, A., Stempel, A. V., et al. (2021). Flexible inhibitory control of visually evoked defensive behavior by the ventral lateral geniculate nucleus. Neuron 109, 3810-3822.e9.

Friend, D. M., and Kravitz, A. V. (2014). Working together: Basal ganglia pathways in action selection. Trends in Neurosciences 37, 301-303. doi:10.1016/j.tins.2014.04.004.

Gale, S. D., and Murphy, G. J. (2014). Distinct representation and distribution of visual information by specific cell types in mouse superficial superior colliculus. Journal of Neuroscience 34, 13458-13471. doi:10.1523/JNEUROSCI.2768-14.2014.

Gale, S. D., and Murphy, G. J. (2018). Distinct cell types in the superficial superior colliculus project to the dorsal lateral geniculate and lateral posterior thalamic nuclei. Journal of Neurophysiology 120, 1286-1292. doi:10.1152/jn.00248.2018.

Gao, Z., Davis, C., Thomas, A. M., Economo, M. N., Abrego, A. M., Svoboda, K., et al. (2018). A cortico-cerebellar loop for motor planning. Nature 563, 113-116. doi:10.1038/s41586-018-0633-X.

Garrett, M. E., Nauhaus, I., Marshel, J. H., Callaway, E. M., Garrett, M. E., Marshel, J. H., et al. (2014). Topography and areal organization of mouse visual cortex. Journal of Neuroscience 34, 12587-12600. doi:10.1523/JNEUROSCI.1124-14.2014.

Gold, J. I., and Shadlen, M. N. (2007). The neural basis of decision making. Annual review of neuroscience 30, 535-574.

doi:10.1146/ANNUREV.NEURO.29.051605.113038. 
Guillaumin, A., Serra, G. pietro, Georges, F., and Wallén-Mackenzie, Å. (2021). Experimental investigation into the role of the subthalamic nucleus (STN) in motor control using optogenetics in mice. Brain Research 1755, 147226. doi:10.1016/J.BRAINRES.2020.147226.

Guo, Z. v., Inagaki, H. K., Daie, K., Druckmann, S., Gerfen, C. R., and Svoboda, K. (2017). Maintenance of persistent activity in a frontal thalamocortical loop. Nature 545, 181-186. doi:10.1038/nature22324.

Guo, Z. v., Li, N., Huber, D., Ophir, E., Gutnisky, D., Ting, J. T., et al. (2014). Flow of cortical activity underlying a tactile decision in mice. Neuron 81, 179-194. doi:10.1016/j.neuron.2013.10.020.

Han, S., Soleiman, M., Soden, M., Zweifel, L., and Palmiter, R. D. (2015). Elucidating an Affective Pain Circuit that Creates a Threat Memory. Cell 162, 363-374. doi:10.1016/J.CELL.2015.05.057.

Han, W., Tellez, L. A., Rangel, M. J., Motta, S. C., Zhang, X., Perez, I. O., et al. (2017). Integrated Control of Predatory Hunting by the Central Nucleus of the Amygdala. Cell 168, 311-324.e18. doi:10.1016/j.cell.2016.12.027.

Hao, Y., Thomas, A. M., and Li, N. (2021). Fully autonomous mouse behavioral and optogenetic experiments in home-cage. eLife 10. doi:10.7554/eLife.66112.

Heindorf, M., Arber, S., and Keller, G. B. (2018). Mouse Motor Cortex Coordinates the Behavioral Response to Unpredicted Sensory Feedback. Neuron 99, 10401054.e5. doi:10.1016/j.neuron.2018.07.046.

Hira, R., Terada, S. I., Kondo, M., and Matsuzaki, M. (2015). Distinct functional modules for discrete and rhythmic forelimb movements in the mouse motor cortex. Journal of Neuroscience 35, 13311-13322. doi:10.1523/JNEUROSCI.2731-15.2015.

Holmgren, C. D., Stahr, P., Wallace, D. J., Voit, K. M., Matheson, E. J., Sawinski, J., et al. (2021). Visual pursuit behavior in mice maintains the pursued prey on the retinal region with least optic flow. eLife 10. doi:10.7554/ELIFE.70838.

Hormigo, S., Zhou, J., and Castro-Alamancos, M. A. (2021). Bidirectional Control of Orienting Behavior by the Substantia Nigra Pars Reticulata: Distinct Significance of Head and Whisker Movements. eNeuro 8. doi:10.1523/ENEURO.0165-21.2021.

Hoy, J. L., Bishop, H. I., and Niell, C. M. (2019). Defined Cell Types in Superior Colliculus Make Distinct Contributions to Prey Capture Behavior in the Mouse. Current Biology 29, 4130-4138.e5. doi:10.1016/j.cub.2019.10.017.

Hoy, J. L., Yavorska, I., Wehr, M., and Niell, C. M. (2016). Vision Drives Accurate Approach Behavior during Prey Capture in Laboratory Mice. Current Biology 26, 3046-3052. doi:10.1016/j.cub.2016.09.009.

Hu, F., and Dan, Y. (2022). An inferior-superior colliculus circuit controls auditory cuedirected visual spatial attention. Neuron 110, 109-119.e3. doi:10.1016/J.NEURON.2021.10.004.

Hu, F., Kamigaki, T., Zhang, Z., Zhang, S., Dan, U., and Dan, Y. (2019). Prefrontal Corticotectal Neurons Enhance Visual Processing through the Superior Colliculus and Pulvinar Thalamus. Neuron 104, 1141-1152.e4. doi:10.1016/J.NEURON.2019.09.019.

Huang, M., Li, D., Cheng, X., Pei, Q., Xie, Z., Gu, H., et al. (2021). The tectonigral pathway regulates appetitive locomotion in predatory hunting in mice. Nature Communications 12, 1-17. doi:10.1038/s41467-021-24696-3.

Huda, R., Sipe, G. O., Breton-Provencher, V., Cruz, K. G., Pho, G. N., Adam, E., et al. (2020). Distinct prefrontal top-down circuits differentially modulate sensorimotor behavior. Nature Communications 11. doi:10.1038/s41467-020-19772-z. 
Hughes, R. N., Watson, G. D. R., Petter, E. A., Kim, N., Bakhurin, K. I., and Yin, H. H. (2019). Precise Coordination of Three-Dimensional Rotational Kinematics by Ventral Tegmental Area GABAergic Neurons. Current Biology 29, 3244-3255.e4. doi:10.1016/j.cub.2019.08.022.

Inagaki, H. K., Chen, S., Ridder, M. C., Sah, P., Li, N., Yang, Z., et al. (2020). A midbrain - thalamus - cortex circuit reorganizes cortical dynamics to initiate planned movement. bioRxiv, 2020.12.16.423127. doi:10.1101/2020.12.16.423127.

Isa, K., Sooksawate, T., Kobayashi, K., Kobayashi, K., Redgrave, P., and Isa, T. (2020). Dissecting the tectal output channels for orienting and defense responses. eNeuro 7, 1-18. doi:10.1523/ENEURO.0271-20.2020.

Isa, T., Marquez-Legorreta, E., Grillner, S., and Scott, E. K. (2021). The tectum/superior colliculus as the vertebrate solution for spatial sensory integration and action. Current Biology 31, R741-R762. doi:10.1016/j.cub.2021.04.001.

Ito, S., Si, Y., Feldheim, D. A., and Litke, A. M. (2020). Spectral cues are necessary to encode azimuthal auditory space in the mouse superior colliculus. Nature Communications 11, 1-12. doi:10.1038/s41467-020-14897-7.

Itokazu, T., Hasegawa, M., Kimura, R., Osaki, H., Albrecht, U. R., Sohya, K., et al. (2018). Streamlined sensory motor communication through cortical reciprocal connectivity in a visually guided eye movement task. Nature Communications 9, 114. doi:10.1038/s41467-017-02501-4.

Jazayeri, M., and Afraz, A. (2017). Navigating the Neural Space in Search of the Neural Code. Neuron 93, 1003-1014. doi:10.1016/J.NEURON.2017.02.019.

Johnson, K. P., Fitzpatrick, M. J., Zhao, L., Wang, B., McCracken, S., Williams, P. R., et al. (2021). Cell-type-specific binocular vision guides predation in mice. Neuron 109, 1527-1539.e4. doi:10.1016/j.neuron.2021.03.010.

Krauzlis, R. J., Lovejoy, L. P., and Zénon, A. (2013). Superior Colliculus and Visual Spatial Attention. Annual review of neuroscience 36, 165-182. doi:10.1146/ANNUREV-NEURO-062012-170249.

Kunwar, P. S., Zelikowsky, M., Remedios, R., Cai, H., Yilmaz, M., Meister, M., et al. (2015). Ventromedial hypothalamic neurons control a defensive emotion state. elife 2015. doi:10.7554/eLife.06633.

Lecca, S., Namboodiri, V. M. K., Restivo, L., Gervasi, N., Pillolla, G., Stuber, G. D., et al. (2020). Heterogeneous Habenular Neuronal Ensembles during Selection of Defensive Behaviors. Cell Reports 31, 107752. doi:10.1016/j.celrep.2020.107752.

Lee, H., Kim, D. W., Remedios, R., Anthony, T. E., Chang, A., Madisen, L., et al. (2014). Scalable control of mounting and attack by Esr1+ neurons in the ventromedial hypothalamus. Nature 509, 627-632. doi:10.1038/nature13169.

Lee, J., and Sabatini, B. L. (2021). Striatal indirect pathway mediates exploration via collicular competition. Nature 2021 599:7886 599, 645-649. doi:10.1038/s41586021-04055-4.

Lee, J., Wang, W., and Sabatini, B. L. (2020a). Anatomically segregated basal ganglia pathways allow parallel behavioral modulation. Nature Neuroscience, 1-11. doi:10.1038/s41593-020-00712-5.

Lee, K. H., Tran, A., Turan, Z., and Meister, M. (2020b). The sifting of visual information in the superior colliculus. eLife 9. doi:10.7554/eLife.50678.

Li, L., Feng, X., Zhou, Z., Zhang, H., Shi, Q., Lei, Z., et al. (2018a). Stress Accelerates Defensive Responses to Looming in Mice and Involves a Locus Coeruleus-Superior Colliculus Projection. Current Biology 28, 859-871.e5. doi:10.1016/j.cub.2018.02.005. 
Li, Y., Zeng, J., Zhang, J., Yue, C., Zhong, W., Liu, Z., et al. (2018b). Hypothalamic Circuits for Predation and Evasion. Neuron 97, 911-924.e5. doi:10.1016/j.neuron.2018.01.005.

Li, Z., Wei, J. X., Zhang, G. W., Huang, J. J., Zingg, B., Wang, X., et al. (2021). Corticostriatal control of defense behavior in mice induced by auditory looming cues. Nature Communications 12, 1-13. doi:10.1038/s41467-021-21248-7.

Liang, F., Xiong, X. R., Zingg, B., Ji, X., Zhang, L. I., and Tao, H. W. (2015). Sensory Cortical Control of a Visually Induced Arrest Behavior via Corticotectal Projections. Neuron 86, 755-767. doi:10.1016/J.NEURON.2015.03.048.

Liu, D., Li, W., Ma, C., Zheng, W., Yao, Y., Tso, C. F., et al. (2020). A common hub for sleep and motor control in the substantia nigra. Science 367, 440-445. doi:10.1126/SCIENCE.AAZ0956/SUPPL FILE/AAZ0956-LIU-SM.PDF.

Masullo, L., Mariotti, L., Alexandre, N., Freire-Pritchett, P., Boulanger, J., and Tripodi, M. (2019). Genetically Defined Functional Modules for Spatial Orienting in the Mouse Superior Colliculus. Current Biology 29, 2892-2904.e8. doi:10.1016/j.cub.2019.07.083.

May, P. J. (2006). The mammalian superior colliculus: Laminar structure and connections. Progress in Brain Research 151, 321-378. doi:10.1016/S00796123(05)51011-2.

Mayrhofer, J. M., El-Boustani, S., Foustoukos, G., Auffret, M., Tamura, K., and Petersen, C. C. H. (2019). Distinct Contributions of Whisker Sensory Cortex and Tongue-Jaw Motor Cortex in a Goal-Directed Sensorimotor Transformation. Neuron 103, 1034-1043.e5. doi:10.1016/j.neuron.2019.07.008.

McElvain, L. E., Chen, Y., Moore, J. D., Brigidi, G. S., Bloodgood, B. L., Lim, B. K., et al. (2021). Specific populations of basal ganglia output neurons target distinct brain stem areas while collateralizing throughout the diencephalon. Neuron 109, 17211738.e4. doi:10.1016/J.NEURON.2021.03.017.

Michaiel, A. M., Abe, E. T. T., and Niell, C. M. (2020). Dynamics of gaze control during prey capture in freely moving mice. eLife 9, 1-27. doi:10.7554/eLife.57458.

Miller, K. D. (2016). Canonical computations of cerebral cortex. Current Opinion in Neurobiology 37, 75-84. doi:10.1016/j.conb.2016.01.008.

Montardy, Q., Zhou, Z., Li, L., Yang, Q., Lei, Z., Feng, X., et al. (2021). Dopamine modulates visual threat processing in the superior 1 colliculus via D2 receptors 23 . bioRxiv, 2021.02.12.430615. doi:10.1101/2021.02.12.430615.

Morandell, K., and Huber, D. (2017). The role of forelimb motor cortex areas in goal directed action in mice. Scientific Reports 7, 1-14. doi:10.1038/s41598-017-158352.

Mrsic-Flogel, T. D., Hofer, S. B., Creutzfeldt, C., Cloëz-Tayarani, I., Changeux, J. P., Bonhoeffer, T., et al. (2005). Altered map of visual space in the superior colliculus of mice lacking early retinal waves. Journal of Neuroscience 25, 6921-6928. doi:10.1523/JNEUROSCI.1555-05.2005.

Odoemene, O., Pisupati, S., Nguyen, H., and Churchland, A. K. (2018). Visual evidence accumulation guides decision-making in unrestrained mice. Journal of Neuroscience 38, 10143-10155. doi:10.1523/JNEUROSCI.3478-17.2018.

Perusini, J. N., and Fanselow, M. S. (2015). Neurobehavioral perspectives on the distinction between fear and anxiety. Learning and Memory 22, 417-425. doi:10.1101//m.039180.115.

Procacci, N., and Hoy, J. L. (2019). Hungry for motion: the senses propel predation. Nature Neuroscience 2019 22:6 22, 843-845. doi:10.1038/s41593-019-0412-5. 
Procacci, N. M., Allen, K. M., Robb, G. E., ljekah, R., Lynam, H., and Hoy, J. L. (2020). Context-dependent modulation of natural approach behaviour in mice. Proceedings of the Royal Society B: Biological Sciences 287, 20201189.

doi:10.1098/rspb.2020.1189.

Puelles, E., Martínez-de-la-Torre, M., Watson, C., and Puelles, L. (2012). "Chapter 10 Midbrain," in The Mouse Nervous System, eds. C. Watson, G. Paxinos, and L. Puelles (San Diego: Academic Press), 337-359. doi:https://doi.org/10.1016/B9780-12-369497-3.10010-X.

Reinhard, K., Li, C., Do, Q., Burke, E. G., Heynderickx, S., and Farrow, K. (2019). A projection specific logic to sampling visual inputs in mouse superior colliculus. eLife 8. doi:10.7554/ELIFE.50697.

Ruder, L., Schina, R., Kanodia, H., Valencia-Garcia, S., Pivetta, C., and Arber, S. (2021). A functional map for diverse forelimb actions within brainstem circuitry. Nature 590, 445. doi:10.1038/s41586-020-03080-z.

Salay, L. D., and Huberman, A. D. (2021). Divergent outputs of the ventral lateral geniculate nucleus mediate visually evoked defensive behaviors. Cell Reports 37, 109792. doi:10.1016/J.CELREP.2021.109792.

Sans-Dublanc, A., Chrzanowska, A., Reinhard, K., Lemmon, D., Nuttin, B., Lambert, T., et al. (2021). Optogenetic fUSI for brain-wide mapping of neural activity mediating collicular-dependent behaviors. Neuron 109, 1888-1905.e10. doi:10.1016/j.neuron.2021.04.008.

Shang, C., Chen, Z., Liu, A., Li, Y., Zhang, J., Qu, B., et al. (2018). Divergent midbrain circuits orchestrate escape and freezing responses to looming stimuli in mice. Nature Communications 9, 1-17. doi:10.1038/s41467-018-03580-7.

Shang, C., Liu, A., Li, D., Xie, Z., Chen, Z., Huang, M., et al. (2019). A subcortical excitatory circuit for sensory-triggered predatory hunting in mice. Nature Neuroscience 22, 909-920. doi:10.1038/s41593-019-0405-4.

Shang, C., Liu, Z., Chen, Z., Shi, Y., Wang, Q., Liu, S., et al. (2015). A parvalbuminpositive excitatory visual pathway to trigger fear responses in mice. Science 348, 1472-1477. doi:10.1126/science.aaa8694.

Sooksawate, T., Isa, K., Matsui, R., Kato, S., Kinoshita, M., Kobayashi, K., et al. (2013). Viral vector-mediated selective and reversible blockade of the pathway for visual orienting in mice. Frontiers in Neural Circuits 7, 162. doi:10.3389/fncir.2013.00162.

Steinmetz, N. A., Zatka-Haas, P., Carandini, M., and Harris, K. D. (2019). Distributed coding of choice, action and engagement across the mouse brain. Nature 576, 266-273. doi:10.1038/s41586-019-1787-x.

Stubblefield, E. A., Costabile, J. D., and Felsen, G. (2013). Optogenetic investigation of the role of the superior colliculus in orienting movements. Behavioural Brain Research 255, 55-63. doi:10.1016/j.bbr.2013.04.040.

Sun, L., Liu, R., Guo, F., Wen, M. qing, Ma, X. lin, Li, K. yuan, et al. (2020). Parabrachial nucleus circuit governs neuropathic pain-like behavior. Nature Communications 2020 11:1 11, 1-21. doi:10.1038/s41467-020-19767-w.

Takatoh, J., Park, J. H., Lu, J., Li, S., Thompson, P. M., Han, B. X., et al. (2021). Constructing an adult orofacial premotor atlas in allen mouse ccf. eLife 10. doi:10.7554/ELIFE.67291.

Tokuoka, K., Kasai, M., Kobayashi, K., and Isa, T. (2020). Anatomical and electrophysiological analysis of cholinergic inputs from the parabigeminal nucleus to the superficial superior colliculus. Journal of Neurophysiology 124, 1968-1985. doi:10.1152/JN.00148.2020/ASSET/IMAGES/LARGE/AJNEUR200080F009.JPEG. 
Tovote, P., Esposito, M. S., Botta, P., Chaudun, F., Fadok, J. P., Markovic, M., et al. (2016). Midbrain circuits for defensive behaviour. Nature 534, 206-212. doi:10.1038/nature17996.

Tovote, P., Fadok, J. P., and Lüthi, A. (2015). Neuronal circuits for fear and anxiety. Nature Reviews Neuroscience 16, 317-331. doi:10.1038/nrn3945.

Usseglio, G., Gatier, E., Heuzé, A., Hérent, C., and Bouvier, J. (2020). Control of Orienting Movements and Locomotion by Projection-Defined Subsets of Brainstem V2a Neurons. Current Biology 30, 4665-4681.e6. doi:10.1016/j.cub.2020.09.014.

Vaaga, C. E., Brown, S. T., and Raman, I. M. (2020). Cerebellar modulation of synaptic input to freezing-related neurons in the periaqueductal gray. eLife 9. doi:10.7554/eLife.54302.

Vale, R. (2020). Spatial-memory control of defensive actions. Available at: https://doi.org/10.17863/CAM.55684\%0A.

Vale, R., Campagner, D., lordanidou, P., Arocas, O. P., Tan, Y. L., Stempel, A. V., et al. (2020). A cortico-collicular circuit for accurate orientation to shelter during escape. bioRxiv, 2020.05.26.117598. doi:10.1101/2020.05.26.117598.

Vale, R., Evans, D. A., and Branco, T. (2017). Rapid Spatial Learning Controls Instinctive Defensive Behavior in Mice. Current Biology 27, 1342-1349. doi:10.1016/j.cub.2017.03.031.

Venner, A., de Luca, R., Sohn, L. T., Bandaru, S. S., Verstegen, A. M. J., Arrigoni, E., et al. (2019). An Inhibitory Lateral Hypothalamic-Preoptic Circuit Mediates Rapid Arousals from Sleep. Current Biology 29, 4155-4168.e5. doi:10.1016/j.cub.2019.10.026.

Villalobos, C. A., and Basso, M. A. (2020). Optogenetic activation of the inhibitory nigrocollicular circuit evokes orienting movements in mice. bioRxiv, 2020.05.21.107680. doi:10.1101/2020.05.21.107680.

Wang, H., Chen, J., Xu, X., Sun, W. J., Chen, X., Zhao, F., et al. (2019a). Direct auditory cortical input to the lateral periaqueductal gray controls sound-driven defensive behavior. PLoS Biology 17, e3000417. doi:10.1371/journal.pbio.3000417.

Wang, L., Herman, J. P., and Krauzlis, R. J. (2021). Neuronal modulation in the mouse superior colliculus during covert visual selective attention. bioRxiv, 2021.02.05.429996. doi:10.1101/2021.02.05.429996.

Wang, L., and Krauzlis, R. J. (2018). Visual Selective Attention in Mice. Current Biology 28, 676-685.e4. doi:10.1016/J.CUB.2018.01.038.

Wang, L., Liu, M., Segraves, M. A., and Cang, J. (2015). Visual experience is required for the development of eye movement maps in the mouse superior colliculus. Journal of Neuroscience 35, 12281-12286. doi:10.1523/JNEUROSCI.011715.2015.

Wang, L., McAlonan, K., Goldstein, S., Gerfen, C. R., and Krauzlis, R. J. (2020). A causal role for mouse superior colliculus in visual perceptual decision-making. The Journal of Neuroscience, JN-RM-2642-19. doi:10.1523/JNEUROSCI.2642-19.2020.

Wang, L., Talwar, V., Osakada, T., Kuang, A., Guo, Z., Yamaguchi, T., et al. (2019b). Hypothalamic Control of Conspecific Self-Defense. Cell Reports 26, 1747-1758.e5. doi:10.1016/j.celrep.2019.01.078.

Wang, Q., and Burkhalter, A. (2013). Stream-related preferences of inputs to the superior colliculus from areas of dorsal and ventral streams of mouse visual cortex. Journal of Neuroscience 33, 1696-1705. doi:10.1523/JNEUROSCI.3067-12.2013.

Wang, X., Chou, X., Peng, B., Shen, L., Huang, J. J., Zhang, L. I., et al. (2019c). A cross-modality enhancement of defensive flight via parvalbumin neurons in zonal incerta. eLife 8. doi:10.7554/eLife.42728. 
Wang, X., Yang, H., Pan, L., Hao, S., Wu, X., Zhan, L., et al. (2019d). Brain-wide Mapping of Mono-synaptic Afferents to Different Cell Types in the Laterodorsal Tegmentum. Neuroscience Bulletin 35, 781-790. doi:10.1007/s12264-019-00397-2.

Watson, G. D. R., Hughes, R. N., Petter, E. A., Fallon, I. P., Kim, N., Severino, F. P. U., et al. (2021). Thalamic projections to the subthalamic nucleus contribute to movement initiation and rescue of parkinsonian symptoms. Science Advances 7. doi:10.1126/SCIADV.ABE9192/SUPPL_FILE/ABE9192_SM.PDF.

Wei, P., Liu, N., Zhang, Z., Liu, X., Tang, Y., He, X., et al. (2015). Processing of visually evoked innate fear by a non-canonical thalamic pathway. Nature Communications 6, 6756. doi:10.1038/ncomms7756.

Wolff, S. B., and Ölveczky, B. P. (2018). The promise and perils of causal circuit manipulations. Current Opinion in Neurobiology 49, 84-94. doi:10.1016/J.CONB.2018.01.004.

Xie, Z., Wang, M., Liu, Z., Shang, C., Zhang, C., Sun, L., et al. (2021). Transcriptomic encoding of sensorimotor transformation in the midbrain. eLife 10. doi:10.7554/elife.69825.

Xiong, X. R., Liang, F., Zingg, B., Ji, X. Y., Ibrahim, L. A., Tao, H. W., et al. (2015). Auditory cortex controls sound-driven innate defense behaviour through corticofugal projections to inferior colliculus. Nature Communications 6, 1-12. doi:10.1038/ncomms8224.

Xu, H. ping, Furman, M., Mineur, Y. S., Chen, H., King, S. L., Zenisek, D., et al. (2011). An Instructive Role for Patterned Spontaneous Retinal Activity in Mouse Visual Map Development. Neuron 70, 1115-1127. doi:10.1016/j.neuron.2011.04.028.

Yang, H., Yang, J., Xi, W., Hao, S., Luo, B., He, X., et al. (2016). Laterodorsal tegmentum interneuron subtypes oppositely regulate olfactory cue-induced innate fear. Nature Neuroscience 19, 283-289. doi:10.1038/nn.4208.

Yilmaz, M., and Meister, M. (2013). Rapid Innate Defensive Responses of Mice to Looming Visual Stimuli. Current Biology 23, 2011-2015. doi:10.1016/J.CUB.2013.08.015.

Yu, H., Xiang, X., Chen, Z., Wang, X., Dai, J., Wang, X., et al. (2021). Periaqueductal gray neurons encode the sequential motor program in hunting behavior of mice. Nature Communications 2021 12:1 12, 1-15. doi:10.1038/s41467-021-26852-1.

Zahler, S. H., Taylor, D. E., Wong, J. Y., Adams, J. M., and Feinberg, E. H. (2021). Superior colliculus drives stimulus-evoked directionally biased saccades and attempted 2 head movements in head-fixed mice. eLife 10. doi:10.7554/ELIFE.73081.

Zelikowsky, M., Hui, M., Karigo, T., Choe, A., Yang, B., Blanco, M. R., et al. (2018). The Neuropeptide Tac2 Controls a Distributed Brain State Induced by Chronic Social Isolation Stress. Cell 173, 1265-1279.e19. doi:10.1016/j.cell.2018.03.037.

Zhang, Z., Liu, W. Y., Diao, Y. P., Xu, W., Zhong, Y. H., Zhang, J. Y., et al. (2019). Superior Colliculus GABAergic Neurons Are Essential for Acute Dark Induction of Wakefulness in Mice. Current Biology 29, 637-644.e3. doi:10.1016/j.cub.2018.12.031.

Zhao, Z. dong, Chen, Z., Xiang, X., Hu, M., Xie, H., Jia, X., et al. (2019). Zona incerta GABAergic neurons integrate prey-related sensory signals and induce an appetitive drive to promote hunting. Nature Neuroscience 22, 921-932. doi:10.1038/s41593019-0404-5.

Zhou, N. A., Maire, P. S., Masterson, S. P., and Bickford, M. E. (2017). The mouse pulvinar nucleus: organization of the tectorecipient zones. Visual neuroscience 34, E011. doi:10.1017/S0952523817000050. 
Zhou, Z., Liu, X., Chen, S., Zhang, Z., Liu, Y., Montardy, Q., et al. (2019). A VTA GABAergic Neural Circuit Mediates Visually Evoked Innate Defensive Responses. Neuron 103, 473-488.e6. doi:10.1016/j.neuron.2019.05.027.

Zhu, Z., Ma, Q., Miao, L., Yang, H., Pan, L., Li, K., et al. (2021). A substantia innominata-midbrain circuit controls a general aggressive response. Neuron. doi:10.1016/j.neuron.2021.03.002.

Zingg, B., Chou, X. lin, Zhang, Z. gang, Mesik, L., Liang, F., Tao, H. W., et al. (2017). AAV-Mediated Anterograde Transsynaptic Tagging: Mapping Corticocollicular Input-Defined Neural Pathways for Defense Behaviors. Neuron 93, 33-47. doi:10.1016/j.neuron.2016.11.045. 
Supplementary Table 1: Acronyms and corresponding brain areas used in the text. Acronyms and nomenclature are according to that used by the Allen Brain Institute, unless otherwise indicated by an associated citation.

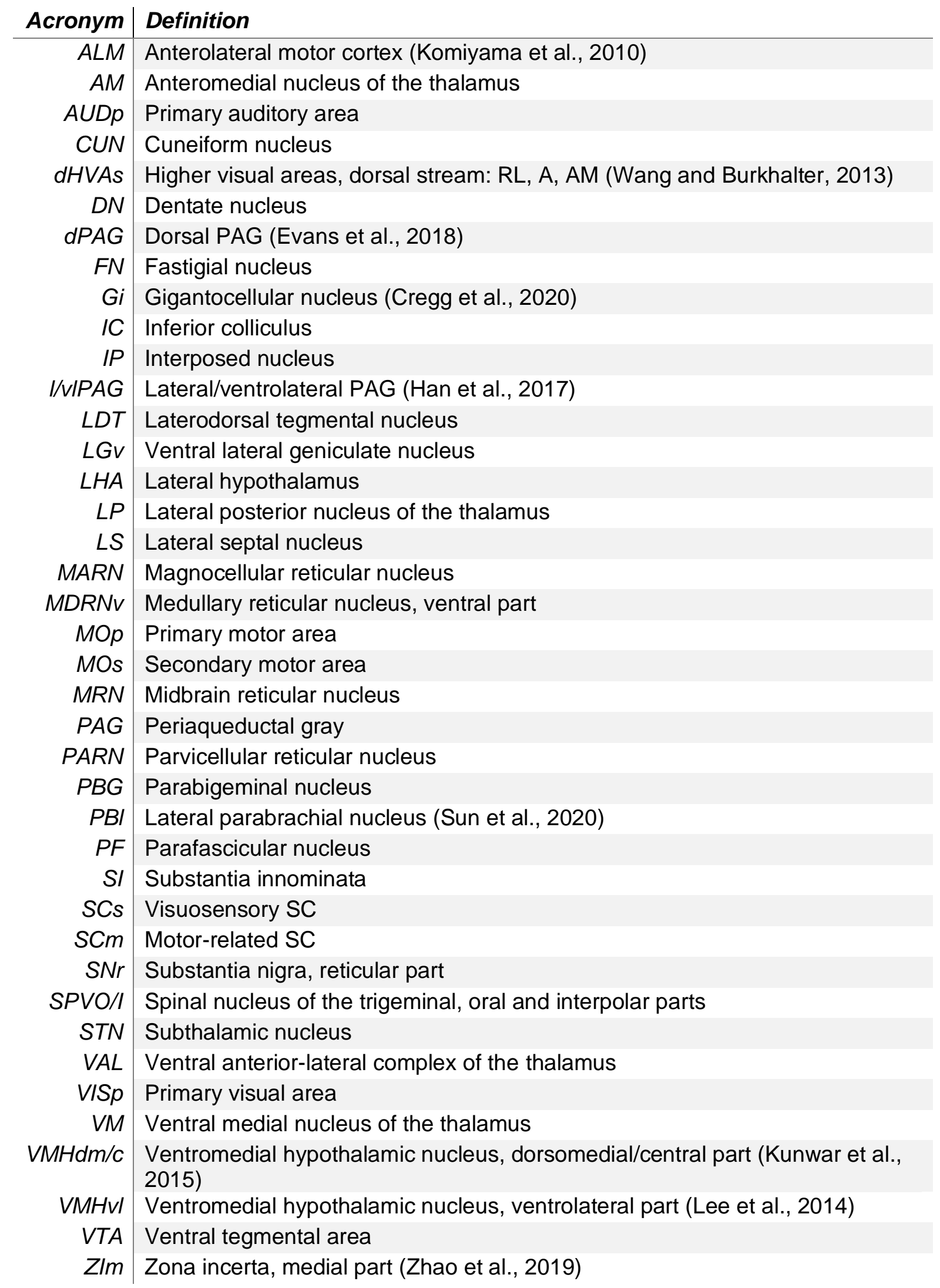


Table 1: Areas reported to be involved in the production of arrest behaviour. Functional measurements and anatomical connectivity with SC.

For example, Shang et al., 2018 ( $4^{\text {th }}$ line in PBG below) shows that; VGLUT2+ PBG neurons show increased activity during arrest; unilateral activation of VGLUT2+ PBG neurons induces arrest; bilateral inhibition of VGLUT2+ PBG neurons impairs arrest. This does not imply that these functional observations would hold in all contexts, nor that VGLUT2+ PBG neurons are the only cell type involved in arrest, nor that all VGLUT2+ PBG neurons are involved in arrest. The study also finds that PV+ SC neurons project to the PBG: though this does not imply that PV+ SC neurons are the only PBGprojectors in the SC, or that all PV+ SC neurons project to the PBG. Finally, the study further suggests a role for the PBG in fast locomotion.

ARREST

\begin{tabular}{|c|c|c|c|c|c|c|c|c|c|c|c|}
\hline \multirow[t]{3}{*}{ AREA } & \multirow[t]{3}{*}{ Reference } & \multicolumn{4}{|c|}{ Function } & \multicolumn{6}{|c|}{ Anatomy } \\
\hline & & \multirow{2}{*}{$\begin{array}{l}\text { Neural } \\
\text { activity } \\
\text { increases } \\
\text { during } \\
\text { arrest }\end{array}$} & \multirow{2}{*}{$\begin{array}{l}\text { Activation } \\
\text { induces } \\
\text { arrest }\end{array}$} & \multirow{2}{*}{$\begin{array}{l}\text { Inhibition } \\
\text { impairs arrest }\end{array}$} & \multirow[t]{2}{*}{ Other roles } & \multicolumn{3}{|c|}{ Output from ipsilateral SC } & \multicolumn{3}{|c|}{ Input to ipsilateral SC } \\
\hline & & & & & & $\begin{array}{l}\text { Layers and } \\
\text { columns of SC }\end{array}$ & $\begin{array}{l}\text { Cellular } \\
\text { markers in SC }\end{array}$ & $\begin{array}{l}\text { Cellular } \\
\text { markers } \\
\text { in target } \\
\text { area }\end{array}$ & $\begin{array}{l}\text { Layers and } \\
\text { columns of SC }\end{array}$ & $\begin{array}{l}\text { Cellular } \\
\text { markers } \\
\text { in SC }\end{array}$ & $\begin{array}{l}\text { Cellular } \\
\text { markers } \\
\text { in } \\
\text { source } \\
\text { area }\end{array}$ \\
\hline \multirow[t]{7}{*}{ PBG } & Benavidez et al., 2021 & & & & & SCs (c. 1-3) & & & & & \\
\hline & Gale \& Murphy, 2018 & & & & & & $\begin{array}{l}\text { GRP+, GAD2+. } \\
\text { or RORB+ }\end{array}$ & & & & \\
\hline & Montardy et al., 2021 & & & & & & DRD2+ & & & & \\
\hline & Shang et al., 2018 & VGLUT2+ & $\begin{array}{l}\text { VGLUT2+ } \\
\text { (unilateral) }\end{array}$ & $\begin{array}{l}\text { VGLUT2+ } \\
\text { (bilateral) }\end{array}$ & $\begin{array}{l}\text { Fast } \\
\text { locomotion }\end{array}$ & & $\mathrm{PV}+$ & & & & \\
\hline & Tokuoka et al., 2020 & & & & & & & & $\begin{array}{l}\text { SCs } \\
\text { (BILATERAL) }\end{array}$ & & CHAT+ \\
\hline & Zhang et al., 2019 & & & & & & VGAT+ & & & & \\
\hline & Zingg et al., 2017 & & & & & & $\begin{array}{l}\text { Retina- or VISp- } \\
\text { or AUDp- } \\
\text { recipient }\end{array}$ & & & & \\
\hline \multirow[t]{4}{*}{ LDT } & Benavidez et al., 2021 & & & & & $\mathrm{SCm}$ (c.1-3) & & & & & \\
\hline & X Wang et al., 2019 & & & & & & & $\begin{array}{l}\mathrm{PV}+\text { or } \\
\mathrm{SOM}+\end{array}$ & & & \\
\hline & Xie et al., 2021 & & & & & & CBLN2+ & & & & \\
\hline & Yang et al., 2016 & & $\begin{array}{l}\mathrm{PV}+ \\
\text { (unilateral) }\end{array}$ & PV+ (unilateral) & $\begin{array}{l}\text { SOM+ in } \\
\text { opposing } \\
\text { arrest }\end{array}$ & & & & & & \\
\hline \multirow[t]{2}{*}{ L/VLPAG } & Tovote et al., 2016 & & $\begin{array}{l}\text { VGLUT2+ } \\
\text { (bilateral) }\end{array}$ & $\begin{array}{l}\text { VGLUT2+ } \\
\text { (bilateral) }\end{array}$ & & & & & & & \\
\hline & $\begin{array}{l}\text { Vaaga, Brown and Raman, } \\
2020\end{array}$ & & $\begin{array}{l}\text { CHX10+ } \\
\text { (bilateral) }\end{array}$ & & & & & & & & \\
\hline
\end{tabular}




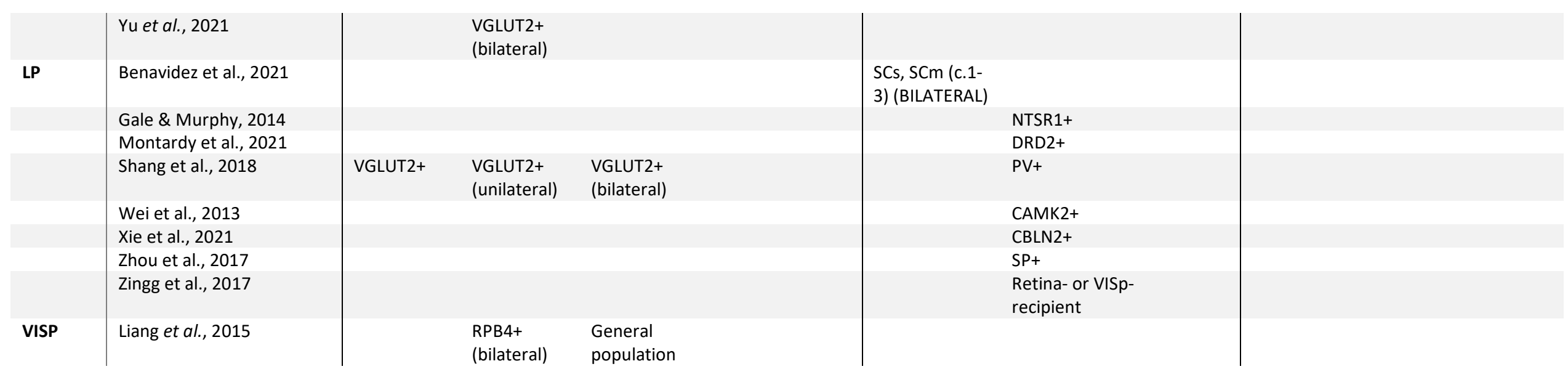


Table 2: Areas reported to be involved in the production of turning. Functional measurements and anatomical connectivity with SC. Conventions as in Table 1.

TURNING

\begin{tabular}{|c|c|c|c|c|c|c|c|c|c|c|c|}
\hline \multicolumn{12}{|c|}{ HEAD OR BODY } \\
\hline \multirow[t]{3}{*}{ AREA } & \multirow[t]{3}{*}{ Reference } & \multicolumn{4}{|c|}{ Function } & \multicolumn{6}{|c|}{ Anatomy } \\
\hline & & \multirow{2}{*}{$\begin{array}{l}\text { Neural } \\
\text { activity } \\
\text { increased } \\
\text { during turns }\end{array}$} & \multirow{2}{*}{$\begin{array}{l}\text { Unilateral } \\
\text { activation } \\
\text { biases } \\
\text { turning }\end{array}$} & \multirow{2}{*}{$\begin{array}{l}\text { Unilateral } \\
\text { inhibition } \\
\text { biases turning }\end{array}$} & \multirow[t]{2}{*}{ Other roles } & \multicolumn{3}{|c|}{ Output from ipsilateral SC } & \multicolumn{3}{|c|}{ Input to ipsilateral SC } \\
\hline & & & & & & $\begin{array}{l}\text { Layers and } \\
\text { columns of SC }\end{array}$ & $\begin{array}{l}\text { Cellular } \\
\text { markers in } \\
\text { SC }\end{array}$ & $\begin{array}{l}\text { Cellular } \\
\text { markers in } \\
\text { target area }\end{array}$ & $\begin{array}{l}\text { Layers } \\
\text { and } \\
\text { colum } \\
\text { ns of } \\
\text { SC }\end{array}$ & $\begin{array}{l}\text { Cellular } \\
\text { markers in SC }\end{array}$ & $\begin{array}{l}\text { Cellular } \\
\text { markers } \\
\text { in source } \\
\text { area }\end{array}$ \\
\hline \multirow[t]{4}{*}{ GI } & Benavidez et al., 2021 & & & & & $\begin{array}{l}\text { SCm (c. 3-4) } \\
\text { (CONTRALATE } \\
\text { RAL) }\end{array}$ & & & & & \\
\hline & Cregg et al., 2020 & & $\mathrm{CHX10+}$ & CHX10+ & & $\begin{array}{l}\text { SCm (c. 3-4) } \\
\text { (CONTRALATE } \\
\text { RAL) }\end{array}$ & $\begin{array}{l}\text { Intermediat } \\
\text { e layer, } \\
\text { VGLUT2+ }\end{array}$ & $\mathrm{CHX10+}$ & & & \\
\hline & Duan et al., 2021 & & & & & & $\begin{array}{l}\text { M2- } \\
\text { recipient }\end{array}$ & & & & \\
\hline & Usseglio et al., 2020 & & $\mathrm{CHX10+}$ & $\mathrm{CHX10+}$ & & & & & & & \\
\hline \multirow[t]{5}{*}{ VTA } & Barbano et al., 2020 & & & & Escape & & & & & & \\
\hline & Benavidez et al., 2021 & & & & & $\mathrm{SCm}$ (c. 3-4) & & & & & \\
\hline & Hughes et al., 2019 & VGAT+ & VGAT+ & VGAT+ & Not escape & & & & & & \\
\hline & Zhang et al., 2019 & & & & Escape & & $\begin{array}{l}\text { GAD2+ or } \\
\text { VGAT+ }\end{array}$ & $\mathrm{TH}+$ & & & \\
\hline & Zhou et al., 2019 & & & & & & CAMK2+ & GAD2+ & & & \\
\hline \multirow[t]{2}{*}{ PF } & Benavidez et al., 2021 & & & & & $\mathrm{SCm}$ (c. 1-4) & & & & & \\
\hline & Watson et al., 2019 & $\begin{array}{l}\text { General } \\
\text { population }\end{array}$ & VGLUT2+ & VGLUT2+ & & & & & & & \\
\hline \multirow[t]{2}{*}{ STN } & Benavidez et al., 2021 & & & & & $3-4$ & & & & & \\
\hline & Guillaumin et al., 2021 & $\begin{array}{l}\text { General } \\
\text { population }\end{array}$ & PITX2+ & PITX2+ & & & & & & & \\
\hline \multicolumn{12}{|c|}{ TONGUE OR EYE } \\
\hline \multirow[t]{5}{*}{$\begin{array}{l}\text { MOS, } \\
\text { ALM } \\
\text { AND } \\
\text { FN }\end{array}$} & Benavidez et al., 2021 & & & & & $\mathrm{SCm}$ (c. 3-4) & & & & & \\
\hline & Duan et al., 2021 & & & MOs & & & & & & & \\
\hline & Gao et al., 2018 & $\mathrm{FN}$ & FN & FN & & & & & & & \\
\hline & Guo et al., 2014 & & & ALM & & & & & & & \\
\hline & Itokazu et al., 2018 & MOs & MOs & MOs & & & & & & & \\
\hline
\end{tabular}




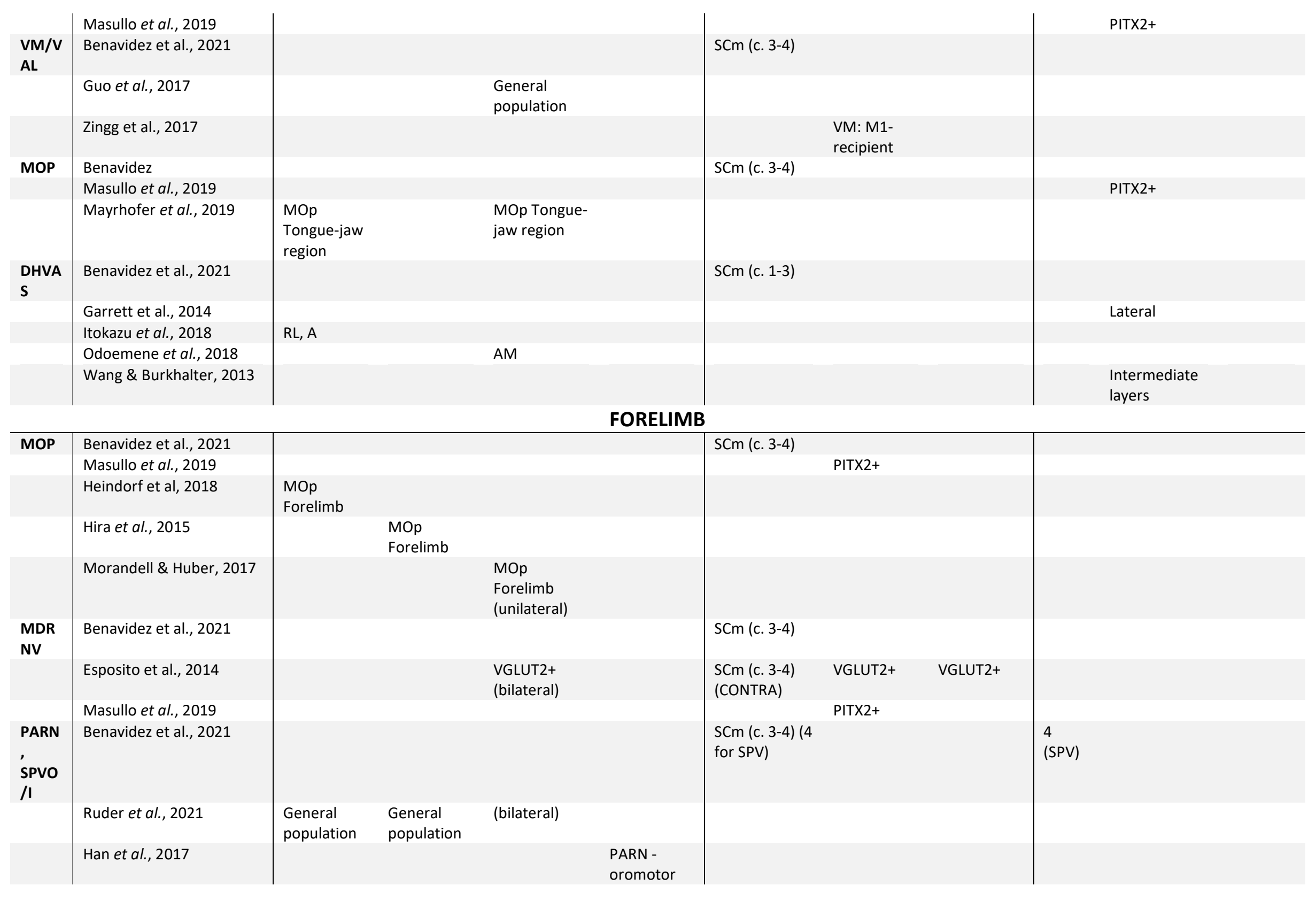


Table 3: Areas reported to be involved in the production of fast locomotion. Functional measurements and anatomical connectivity with SC. Conventions as in Table 1.

\section{FAST LOCOMOTION}

\begin{tabular}{|c|c|c|c|c|c|c|c|c|c|}
\hline \multirow[t]{3}{*}{ AREA } & \multirow[t]{3}{*}{ Reference } & \multicolumn{4}{|c|}{ Function } & \multicolumn{4}{|c|}{ Anatomy } \\
\hline & & \multirow{2}{*}{$\begin{array}{l}\text { Neural } \\
\text { activity } \\
\text { increased } \\
\text { during } \\
\text { behaviour }\end{array}$} & \multirow{2}{*}{$\begin{array}{l}\text { Unilateral } \\
\text { activation } \\
\text { induces } \\
\text { behaviour }\end{array}$} & \multirow{2}{*}{$\begin{array}{l}\text { Bilateral } \\
\text { inhibition } \\
\text { impairs } \\
\text { behaviour }\end{array}$} & \multirow[t]{2}{*}{ Other roles } & \multicolumn{3}{|c|}{ Output from ipsilateral SC } & Input to ipsilateral SC \\
\hline & & & & & & $\begin{array}{l}\text { Layers and } \\
\text { columns of SC }\end{array}$ & $\begin{array}{l}\text { Cellular } \\
\text { markers in } \\
\text { SC }\end{array}$ & $\begin{array}{l}\text { Cellular } \\
\text { markers in } \\
\text { target area }\end{array}$ & $\begin{array}{l}\text { Layers } \\
\text { and } \\
\text { columns } \\
\text { of SC }\end{array}$ \\
\hline \multirow[t]{2}{*}{ AUDP } & Li et al., 2021 & & & $\begin{array}{l}\text { General } \\
\text { population }\end{array}$ & Arrest & & & & \\
\hline & Xiong et al., 2015 & & RPB4+ & $\begin{array}{l}\text { General } \\
\text { population }\end{array}$ & & & & & \\
\hline \multirow[t]{2}{*}{ CUN } & Benavidez et al., 2021 & & & & & $\mathrm{SCm}$ (c. 1) & & & \\
\hline & Caggiano et al., 2018 & & VGLUT2+ & VGLUT2+ & & & & & \\
\hline \multirow[t]{2}{*}{ MARN } & Benavidez et al., 2021 & & & & & $\mathrm{SCm}$ (c. 1-2) & & & \\
\hline & Capelli et al., 2017 & & LPGi VGLUT2+ & $\begin{array}{l}\text { LPGi } \\
\text { VGLUT2+ }\end{array}$ & LPGi VGAT+ in arrest & & & $\begin{array}{l}\text { LPGi } \\
\text { VGLUT2+ }\end{array}$ & \\
\hline \multirow[t]{4}{*}{ IC } & Benavidez et al., 2021 & & & & & $\mathrm{SCm}$ (c. 1-4) & & & $1-4$ \\
\hline & Masullo et al., 2019 & & & & & & PITX2+ & & \\
\hline & Xiong et al., 2015 & & CAMK2+ & $\begin{array}{l}\text { General } \\
\text { population }\end{array}$ & & & & & \\
\hline & Zhang et al., 2019 & & & & & & VGAT+ & & \\
\hline
\end{tabular}


Table 4: Areas reported to be involved in the triggering of capture and escape. Functional measurements and anatomical connectivity with SC. Conventions as in Table 1.

TRIGGERING

\begin{tabular}{|c|c|c|c|c|c|c|c|c|c|c|c|}
\hline \multicolumn{12}{|c|}{ Capture } \\
\hline \multirow[t]{3}{*}{ Area } & \multirow[t]{3}{*}{ Reference } & \multicolumn{4}{|c|}{ Function } & \multicolumn{6}{|c|}{ Anatomy } \\
\hline & & \multirow{2}{*}{$\begin{array}{l}\text { Neural } \\
\text { activity } \\
\text { increased } \\
\text { during } \\
\text { behaviour }\end{array}$} & \multirow{2}{*}{$\begin{array}{l}\text { Unilateral } \\
\text { activation } \\
\text { induces } \\
\text { behaviour }\end{array}$} & \multirow{2}{*}{$\begin{array}{l}\text { Bilateral } \\
\text { inhibition } \\
\text { impairs } \\
\text { behaviour }\end{array}$} & \multirow[t]{2}{*}{ Other roles } & \multicolumn{3}{|c|}{ Output from ipsilateral SC } & \multicolumn{3}{|c|}{ Input to ipsilateral SC } \\
\hline & & & & & & $\begin{array}{l}\text { Layers } \\
\text { and } \\
\text { columns } \\
\text { of SC }\end{array}$ & $\begin{array}{l}\text { Cellular } \\
\text { markers } \\
\text { in SC }\end{array}$ & $\begin{array}{l}\text { Cellular } \\
\text { markers } \\
\text { in target } \\
\text { area }\end{array}$ & $\begin{array}{l}\text { Layers and } \\
\text { columns of SC }\end{array}$ & $\begin{array}{l}\text { Cellular } \\
\text { markers } \\
\text { in SC }\end{array}$ & $\begin{array}{l}\text { Cellular } \\
\text { markers } \\
\text { in source } \\
\text { area }\end{array}$ \\
\hline \multirow[t]{3}{*}{ LHA } & Benavidez et al., 2021 & & & & & $\begin{array}{l}\mathrm{SCm} \text { (c.3- } \\
4)\end{array}$ & & & & & \\
\hline & Li et al., 2018 & VGAT+ & $\begin{array}{l}\text { VGAT+ } \\
\text { bilateral }\end{array}$ & VGAT + & $\begin{array}{l}\text { VGLUT2+ in } \\
\text { evasion }\end{array}$ & & & & & & \\
\hline & Venner et al., 2019 & & & & & & & VGAT+ & & & \\
\hline \multirow[t]{2}{*}{$S I$} & Benavidez et al., 2021 & & & & & & & & 4 & & \\
\hline & Zhu et al., 2021 & THY1+ & $\begin{array}{l}\text { THY1+ or } \\
\text { CAMK2+ }\end{array}$ & THY1+ & & & & & & & \\
\hline L/VLPAG & Yu et al., 2021 & $\begin{array}{l}\text { General } \\
\text { population }\end{array}$ & & VGAT+ & & & & & & & \\
\hline VISP & Burgess et al., 2017 & & & $\begin{array}{l}\text { General } \\
\text { population }\end{array}$ & & & & & & & \\
\hline \multirow[t]{3}{*}{ VMHvl } & Benavidez et al., 2021 & & & & & & & & $\begin{array}{l}\text { 3-4 } \\
\text { (BILATERAL) }\end{array}$ & $\begin{array}{l}\text { Lateral- } \\
\text { biased }\end{array}$ & \\
\hline & L Wang, et al., 2019 & ESR1+ & & & $\begin{array}{l}\text { Social } \\
\text { defence }\end{array}$ & & & & & & \\
\hline & Lee et al., 2014 & & ESR1+ & ESR1+ & & & & & & & \\
\hline \multirow[t]{6}{*}{ ZIm } & Ahmadlou et al., 2021 & & $\begin{array}{l}\text { GAD2+ or } \\
\text { TAC1+ }\end{array}$ & $\begin{array}{l}\text { GAD2+ or } \\
\text { TAC1+ }\end{array}$ & & & & & & & \\
\hline & Benavidez et al., 2021 & & & & & $\mathrm{SCm}$ (c. 4) & $\begin{array}{l}\text { Lateral- } \\
\text { biased }\end{array}$ & & 4 & $\begin{array}{l}\text { Lateral- } \\
\text { biased }\end{array}$ & \\
\hline & Masullo et al., 2019 & & & & & & PITX2+ & & & & \\
\hline & X. Wang et al., 2019 & & & & Defence & & & & & & \\
\hline & Xie et al., 2021 & & & & & & PITX2+ & & & & \\
\hline & Zhao et al., 2019 & & $\begin{array}{l}\text { VGAT+ } \\
\text { bilateral }\end{array}$ & VGAT+ & & & & & & & \\
\hline$M R N$ & Benavidez et al., 2021 & & & & & $\begin{array}{l}\text { SCm (c. 3- } \\
\text { 4) }\end{array}$ & & & $\mathrm{SCm}$ (c. 3-4) & & \\
\hline
\end{tabular}




\begin{tabular}{|c|c|c|c|c|c|c|c|c|}
\hline & Inagaki et al., 2020 & & & $\begin{array}{l}\text { Thalamus- } \\
\text { projecting } \\
\text { MRN/PPN }\end{array}$ & & & & \\
\hline & Masullo et al., 2019 & & & & & PITX2+ & & PITX2+ \\
\hline \multirow[t]{3}{*}{$D N \& I P N$} & Benavidez et al., 2021 & & & & & & $\mathrm{SCm}$ (c. 3-4) & \\
\hline & Dacre et al., 2021 & & $\begin{array}{l}\text { General } \\
\text { population }\end{array}$ & & & & & \\
\hline & Masullo et al., 2019 & & & & & & & PITX2+ \\
\hline \multirow[t]{2}{*}{$A M \& V A L$} & Benavidez et al., 2021 & & & & & & $\mathrm{SCm}$ (c. 3-4) & \\
\hline & Dacre et al., 2021 & & $\begin{array}{l}\text { General } \\
\text { population }\end{array}$ & & & & & \\
\hline \multicolumn{9}{|c|}{ Escape } \\
\hline \multirow[t]{4}{*}{ DPAG } & Deng et al., 2016 & & & & $\begin{array}{l}\text { Interspersed } \\
\text { with arrest }\end{array}$ & & & \\
\hline & Evans et al., 2018 & VGLUT2+ & $\begin{array}{l}\text { VGLUT2+ } \\
\text { bilateral }\end{array}$ & VGLUT2+ & & $\begin{array}{l}\text { Medial- } \\
\text { biased }\end{array}$ & & \\
\hline & Kunwar et al., 2015 & & & & $\begin{array}{l}\text { Interspersed } \\
\text { with arrest }\end{array}$ & & & \\
\hline & Tovote et al., 2016 & & & & $\begin{array}{l}\text { Interspersed } \\
\text { with arrest }\end{array}$ & & & \\
\hline \multirow[t]{3}{*}{$P B I$} & Benavidez et al., 2021 & & & & & $\mathrm{SCm}$ (c. 1) & & \\
\hline & Han et al., 2015 & CGRP+ & & CGRP+ & Arrest & & & \\
\hline & Sun et al., 2020 & & $\begin{array}{l}\text { VGLUT2+, } \\
\text { CAMK2+ }\end{array}$ & & & & & \\
\hline \multirow[t]{2}{*}{$L S$} & Benavidez et al., 2021 & & & & & $\mathrm{SCm}$ (c. 1) & & \\
\hline & Azevedo et al., 2020 & NTS+ & & & & & & \\
\hline \multirow[t]{2}{*}{$V M H d m / c$} & Benavidez et al., 2021 & & & & & & $\begin{array}{l}1-2 \\
\text { (BILATERAL) }\end{array}$ & $\begin{array}{l}\text { Medial- } \\
\text { biased }\end{array}$ \\
\hline & Kunwar et al., 2015 & & $\begin{array}{l}\text { SF1+ } \\
\text { bilateral }\end{array}$ & & Arrest & & & \\
\hline
\end{tabular}


Table 5: Areas providing inhibitory input to the SC. Functional measurements and anatomical connectivity with SC. Conventions as in Table 1.

\begin{tabular}{|c|c|c|c|c|c|c|c|}
\hline \multicolumn{8}{|c|}{ INHIBITORY INPUTS } \\
\hline \multirow[t]{3}{*}{ AREA } & \multirow[t]{3}{*}{ Reference } & \multicolumn{3}{|c|}{ Function } & \multirow{2}{*}{\multicolumn{3}{|c|}{$\begin{array}{c}\text { Anatomy } \\
\text { Input to ipsilateral SC }\end{array}$}} \\
\hline & & \multirow[b]{2}{*}{$\begin{array}{l}\text { Neural } \\
\text { activity } \\
\text { increased } \\
\text { during } \\
\text { behaviour }\end{array}$} & \multirow{2}{*}{$\begin{array}{l}\text { Unilateral activation } \\
\text { induces behaviour }\end{array}$} & \multirow{2}{*}{$\begin{array}{l}\text { Bilateral inhibition impairs } \\
\text { behaviour }\end{array}$} & & & \\
\hline & & & & & $\begin{array}{l}\text { Layers and } \\
\text { columns of SC }\end{array}$ & $\begin{array}{l}\text { Cellular markers in } \\
\text { SC }\end{array}$ & $\begin{array}{l}\text { Cellular markers in } \\
\text { source area }\end{array}$ \\
\hline \multirow[t]{3}{*}{ LGV } & Benavidez et al., 2021 & & & & $\mathrm{SCm}$ (c. 1-3) & & \\
\hline & Fratzl et al., 2021 & & & & All layers & $\begin{array}{l}\text { Medial-biased } \\
\text { VGAT+ or GAD2+ or } \\
\text { VGLUT2+ }\end{array}$ & \\
\hline & Salay \& Huberman, 2021 & & & & & $\begin{array}{l}\text { VGAT+ or GAD2+ or } \\
\text { VGLUT2+ }\end{array}$ & \\
\hline \multirow[t]{2}{*}{$\begin{array}{l}\text { LGV } \\
\text { (ARREST) }\end{array}$} & Fratzl et al., 2021 & & $\begin{array}{l}\text { VGAT+ activation } \\
\text { impairs arrest }\end{array}$ & & & & \\
\hline & Salay \& Huberman, 2021 & & $\begin{array}{l}\text { GAD2+ impairs \& } \\
\text { VGLUT2+ induces } \\
\text { arrest }\end{array}$ & $\begin{array}{l}\text { GAD2+ facilitates \& } \\
\text { VGLUT2+ impairs arrest }\end{array}$ & & & \\
\hline $\begin{array}{l}\text { LGV } \\
\text { (ESCAPE) }\end{array}$ & Fratzl et al., 2021 & & VGAT+ impairs escape & VGAT+ facilitates escape & & & \\
\hline \multirow{6}{*}{$\begin{array}{l}\text { SNR } \\
\text { (TURNING) }\end{array}$} & Benavidez et al., 2021 & & & & $\mathrm{SCm}$ (c. 1-4) & & \\
\hline & Hormigo et al., 2021 & & $\begin{array}{l}\text { VGAT+ activation } \\
\text { induces ipsiversive } \\
\text { turns }\end{array}$ & $\begin{array}{l}\text { VGAT+ inhibition induces } \\
\text { contraversive turns }\end{array}$ & & & \\
\hline & Lee et al., 2020 & & & & $\begin{array}{l}\text { Intermediate } \\
\text { layers }\end{array}$ & & \\
\hline & Liu et al., 2020 & & & & & & GAD2+ or PV+ \\
\hline & Masullo et al., 2019 & & & & & PITX2+ & \\
\hline & McElvain et al., 2021 & & & & & & $\mathrm{PV}+$ or VGAT+ \\
\hline
\end{tabular}

